\title{
First Stage of a Highly Reliable Reusable Launch System
}

\author{
Kurt J. Kloesel ${ }^{*}$, Jonathan B. Pickrel ${ }^{\dagger}$, and Emily L. Sayles ${ }^{\ddagger}$ \\ NASA Dryden Flight Research Center, Edwards, California, 93523-0273 \\ Michael Wright ${ }^{\S}$ \\ NASA Goddard Space Flight Center, Greenbelt, Maryland, 20771-0001 \\ Darin Marriott $^{* *}$ \\ Embry-Riddle University, Prescott, Arizona, 86301-3720 \\ Dr. Leo Holland ${ }^{\dagger \dagger}$ \\ General Atomics Electromagnetic Systems Division, San Diego, California, 92121-1194 \\ Dr. Stephen Kuznetsov $¥$ \\ Power Superconductor Applications Corporation, New Castle, Pennsylvania, 16101-5241
}

\begin{abstract}
Electromagnetic launch assist has the potential to provide a highly reliable reusable first stage to a space access system infrastructure at a lower overall cost. This paper explores the benefits of a smaller system that adds the advantages of a high specific impulse air-breathing stage and supersonic launch speeds. The method of virtual specific impulse is introduced as a tool to emphasize the gains afforded by launch assist. Analysis shows launch assist can provide a 278-s virtual specific impulse for a first-stage solid rocket. Additional trajectory analysis demonstrates that a system composed of a launch-assisted first-stage ramjet plus a bipropellant second stage can provide a 48-percent gross lift-off weight reduction versus an all-rocket system. The combination of high-speed linear induction motors and ramjets is identified, as the enabling technologies and benchtop prototypes are investigated. The high-speed response of a standard $60 \mathrm{~Hz}$ linear induction motor was tested with a pulse width modulated variable frequency drive to $150 \mathrm{~Hz}$ using a 10-lb load, achieving $150 \mathrm{mph}$. A 300-Hz stator-compensated linear induction motor was constructed and static-tested to $1900 \mathrm{lbf}$ average. A matching ramjet design was developed for use on the $300-\mathrm{Hz}$ linear induction motor.
\end{abstract}

\section{Nomenclature}

$\begin{array}{ll}\text { COTS } & =\text { commercial off-the-shelf technology } \\ C_{D} & =\text { coefficient of drag } \\ \text { DSLIM } & =\text { double-sided linear induction motor } \\ \text { GECAT } & =\text { Graphical Engine Cycle Analysis Tool } \\ \text { GLOW } & =\text { gross lift-off weight } \\ g & =\text { gravitational acceleration }\left(32.174 \mathrm{ft} / \mathrm{s}^{2}\right) \\ I_{s p} & =\text { specific impulse, } \mathrm{s} \\ I_{s p_{\text {_virtual }}} & =\text { virtual specific impulse, } \mathrm{s} \\ \text { IGBT } & =\text { insulated gate bipolar junction transistor }\end{array}$

*Electrical Engineer, Aerodynamics and Propulsion, P.O. Box 273 / Mail Stop 4840, AIAA member.

${ }^{\dagger}$ Aerospace Engineer, Controls and Dynamics, P.O. Box 273 / Mail Stop 4840.

${ }^{\ddagger}$ MUST Scholar Summer 2008, Aerodynamics and Propulsion, P.O. Box 273 / Mail Stop 4840.

$\S$ Electrical Engineer, Flight Systems Integration and TestM/S 568, NASA-GSFC, Greenbelt, MD.

** Member of Technical Staff, S3-347, Lincoln Labs, 244 Wood Street, Lexington, Massachusetts, 02420-9108.

\#ं Director of Advanced Electromagnetics Reseach, 3550 General Atomics Court, San Diego, California, 92121-1194.

${ }^{\ddagger \ddagger}$ President, Power SuperConductors Applications, Inc, 930 Cass Street, New Castle, Pennsylvania, 16101-5241. 


$\begin{array}{ll}\text { LIM } & =\text { linear induction motor } \\ \text { Mlbs } & =\text { millions of pounds } \\ m_{\text {initial }} & =\text { initial total mass, including propellant, } \mathrm{lb} \\ m_{\text {final }} & =\text { final total mass, lb } \\ \text { OTIS } & =\text { Optimal Trajectories by Implicit Simulation } \\ \text { POST } & =\text { Program to Optimize Simulated Trajectories } \\ \text { STP } & =\text { standard temperature and pressure } \\ \text { TRL } & =\text { technology readiness level } \\ V_{\text {final }} & =\text { final velocity, } \mathrm{ft} / \mathrm{s}^{2} \\ V_{\text {launch_assist }} & =\text { velocity imparted by launch assist, } \mathrm{ft} / \mathrm{s}^{2} \\ v_{\text {exit }} & =\text { exhaust gases exit velocity, } \mathrm{ft} / \mathrm{s}^{2} \\ \Delta V & =\text { delta velocity, } \mathrm{ft} / \mathrm{s} \\ \gamma & =\text { flight path angle, deg }\end{array}$

\section{Introduction}

$\mathrm{T}$ HIS paper focuses on the smaller steps that will be required to bring an operational, full-scale air-breathing launch-assist system to fruition. This paper proposes a system that is composed of a ground-based Mach 1.5 electromagnetic catapult, a Mach 4 reusable ramjet, and a chemical rocket second-stage-to-orbit. Current orbital delivery costs can reach $\$ 10 \mathrm{~K} / \mathrm{lb}$. The focus of the proposed system would be to lower the life cycle costs of a medium-sized launch system. The use of the electromagnetic catapult would reduce gross lift-off weight (GLOW); increasing the reliability and the reusability of the first stage. The use of a reusable air-breathing ramjet booster stage would also reduce GLOW, reduce operational costs, and move orbital launch systems toward greater overall environmental efficiencies. The understanding of the requirements of such a system will require the elevation of the technology readiness level (TRL) levels of the subsystem components.

Electromagnetic launch-assist methods have a history of advocacy going back at least 100 years. An example of an early fully implemented prototype is a 1400-ft synchronous motor called "Electropult" that was developed by the United States Navy and Westinghouse Electric Corporation ${ }^{1,2}$ circa 1946; the intended use was to launch heavily loaded B-25 airplanes from atolls in the Pacific Theater during World War II. Since that time, high-power switching semiconductor device technology has evolved and newer launch-assist devices are appearing, such as the more recent U.S. Navy Electromagnetic Aircraft Launch System (EMALS) program ${ }^{3}$, in which an aircraft carrier steam catapult will be replaced with an electromagnetic launch device. The MagLifter concept proposed by Mankins ${ }^{4}$ suggests a $2.07-\mathrm{Mlbs}$ single-stage-to-orbit (SSTO) vehicle launched at $600 \mathrm{mph}$ as an alternative to the current expendable launch vehicle infrastructure. There are also concepts similar to the mass-driver promoted by Gerard $\mathrm{O}^{\prime} \mathrm{Neill}^{5}$ and others in the 1970s and 1980s for nonchemical launching of small masses from, for example, the lunar surface. Many of these concepts remain in the seed stage because the project cost of such systems is estimated to be in the billions of dollars.

In an effort to raise the system TRL, the current effort suggests that a hybrid chemical-electrical system may be the stepping stone to several future technologies. The practical realization of an air-breathing boost stage can spur the ramjet-scramjet technologies to enable speeds beyond Mach 4. Likewise, the development of a special-purpose supersonic electromagnetic accelerator can advance launch-track technology. It is only through the flight-testing of smaller prototype systems that one can gain insight into the costs and pitfalls that may plague a multibillion-dollar large-scale investment. A simplified trajectory analysis indicates a practical technology maturation path: use existing technologies where possible, elevate the TRL of the enabling technologies, and elevate the TRL of the combined subsystems. Practical demonstrations of high-speed linear induction motors (LIMs) are needed, and a demonstration of supersonic ramjet ignition on a combined linear induction motor system is needed to raise the TRL of the proposed technology. Launch speed, launch angle, launch altitude, and initial system weight are some of the many variables that need to be parameterized to determine the ultimate feasibility of an electromagnetic launch transportation system. Therefore, we begin with some simplified analyses to examine some of the benefits of the hybrid launch-assist air-breathing supersonic launch system.

\section{The Method of Virtual Specific Impulse}

The method of virtual specific impulse $\left(I_{s p_{-} \text {virtual }}\right)$ was developed in order to better highlight the potential gains of a ground-based launch-assist system compared to an all-chemical rocket system. In this method, the ground-based

2

American Institute of Aeronautics and Astronautics 
delta velocity is combined with the chemical rocket booster propulsive system delta velocity. This method was devised as a tool to identify gains in specific impulse relative to a non-launch-assist baseline configuration and is intended to be used only to make such comparisons. The term "virtual" is used because there is actually no mass loss during the launch-assist process. "Virtual" was also chosen instead of "effective" to avoid confusion with any other common terminology that may apply to non-launch-assist types of systems involving the loss of mass.

A fundamental equation of all the changes in velocity for aerospace systems is found in common aerospace textbooks ${ }^{6}$ and is presented in Eq. (1). The steering loss terms are dropped to simplify the expression:

$$
\Delta V_{\text {system }}=\Delta V_{\text {propulsion }}+\Delta V_{\text {drag }}+\Delta V_{\text {gravity }}
$$

Also fundamental is Tsiolkovsky's rocket equation, Eqs. (2) and (3):

$$
\Delta V_{\text {propulsion }}=v_{\text {exit }} \ln \left(\frac{m_{\text {initial }}}{m_{\text {final }}}\right)
$$

where:

$$
v_{\text {exit }}=I_{s p} g_{o}
$$

In the method of virtual specific impulse, the boost in velocity due to launch assist is added to the left side of the equation as such and a new change in velocity due to the propulsion system is defined, as shown in Eq. (4):

$$
\Delta V_{\text {system }}+\Delta V_{\text {launch_assist }}=\Delta V_{\text {virtual }}+\Delta V_{\text {drag }}+\Delta V_{\text {gravity }}
$$

A new $I_{s p_{-} \text {virtual }}$ is computed using the new change in velocity, which includes the contribution of launch assist. If all the other quantities are known, then the new $I_{s p_{-} \text {virtual }}$ can be calculated as shown in Eq. (5):

$$
\Delta V_{\text {system }}+\Delta V_{\text {launch_assist }}-\Delta V_{\text {drag }}-\Delta V_{\text {gravity }}=g_{o} I_{s p_{-} \text {virtual }}
$$

Again, this method is used only as a way to point out and examine the overall system gains through to launch assist. Now that the method is developed, it will be used to examine a suborbital solid rocket system. This examination will include velocities beyond the transonic barrier (Mach 1.5); the reasoning behind the Mach 1.5 number is that it is the starting point velocity for an efficient ramjet. Section III demonstrates the utility of the ground-based launch-assist component of the hybrid air-breathing launch-assist system.

\section{III.The Application of the Virtual Specific Impulse}

The method of virtual specific impulse was applied to a suborbital single-stage solid rocket system with an $I_{s p}$ of $225 \mathrm{~s}$ to analyze the benefits associated with the addition of a launch-assist system. The solid rocket system behavior was first analyzed in a vacuum as a baseline. The trajectory simulation program called OTIS (Optimal Trajectories by Implicit Simulation) was used in the suborbital simulations. The rocket was given various initial velocities which represent delta velocities imparted to the rocket by ground-based launch assist (Table 1) and a percentage increase in specific impulse is calculated.

Table 1. The method of virtual specific impulse applied to a coefficient solid rocket system for vacuum and for sea-level launch cases. The vacuum cases are shown to indicate the performance difference due to drag.

\begin{tabular}{|l|l|l|c|c|}
\hline Case & Drag & $V_{\text {launch_assist }, \mathrm{ft} / \mathrm{s}}$ & $I_{s p \_ \text {virtual }}, \mathrm{s}$ & $\%$ increase \\
\hline 1 & Vacuum & 0 & 225 & 0 \\
\hline 2 & Vacuum & $440(300 \mathrm{mph})$ & 265 & 17.8 \\
\hline 3 & Vacuum & $880(600 \mathrm{mph})$ & 306 & 36 \\
\hline 4 & Vacuum & $1563(\mathrm{Mach} 1.4 \mathrm{STP})$ & 390 & 73.3 \\
\hline 5 & Atmospheric & 0 & 215 & 0 \\
\hline 6 & Atmospheric & $440(300 \mathrm{mph})$ & 227 & 5.6 \\
\hline 7 & Atmospheric & $880(600 \mathrm{mph})$ & 248 & 15.3 \\
\hline 8 & Atmospheric & $1563(\mathrm{Mach} 1.4 \mathrm{STP})$ & 278 & 29.3 \\
\hline
\end{tabular}


The method was then used to examine the relative benefits of the launch-assist system in the atmosphere at sea level standard temperature and pressure (STP) by including the effects of drag on the rocket. For the atmospheric studies, the baseline configuration was modeled after the rocket used by Bui, et al. ${ }^{8}$ Actual flight data (drag profile, burn curve) were incorporated into the OTIS model. A single-stage burn phase was followed by a free-fall coasting phase in the simulations. Again, the method of virtual specific impulse was used to make comparisons between cases of nonzero initial velocity and the baseline case of the rocket with zero initial velocity. The analysis shows that the performance of a solid rocket can be increased from an $I_{s p \_v i r t a a l}$ of 215 to an $I_{s p \_ \text {virtual }}$ of 278 (Table 1). Gains in virtual specific impulse reached almost $30 \%$ when considering the highest initial velocity case.

The benefits of launch assist could also extend to propelling the vehicle through the transonic barrier during its first stage. The transonic region ( $\mathrm{M}=0.8$ to 1.2$)$ is a costly region in terms of drag: drag coefficients increase sharply around Mach 1 due to shock-induced separation of flow. As a comparative tool, a constant drag profile was created in order to show the potential benefit of surpassing the transonic area rise (Fig. 1). This study showed an increase of $13 \%$ in virtual specific impulse simply by leveling the drag profile. Again, a constant drag profile was used only to demonstrate that there is a cost associated with traveling through the transonic region. By using a ground-based launch-assist system to provide a supersonic initial velocity to the vehicle, the cost of transonic flight would not be paid with onboard fuel.

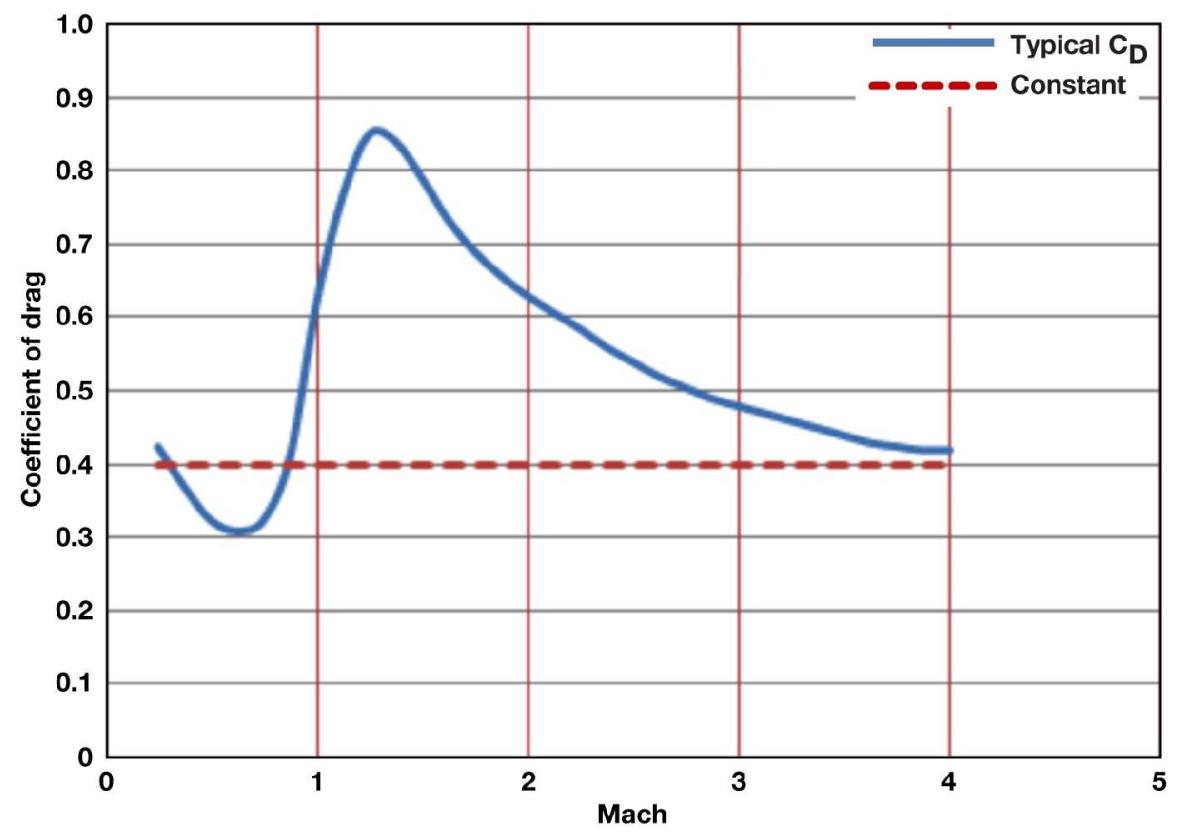

Figure 1. A fictitious constant drag profile is used to demonstrate that a supersonic launch assist also increases the $I_{s p \text { virtual }}$ by overcoming the energy needed to punch through the transonic barrier (Curve reference Humble ).

Thus, from analysis it is concluded that the ground-based launch-assist component of the hybrid air-breathing launch-assist system can provide a useful performance increase in the boost phase. It is also identified that surpassing the transonic barrier could provide additional benefits. The first building block in the foundation of the launch-assist - ramjet-rocket system is established with the virtual specific impulse method. Section IV discusses the addition of the ramjet booster and compare orbital injection trajectories to a traditional all-chemical rocket system.

\section{The All-Chemical Rocket versus the Hybrid Air-Breathing Launch-Assist Low Earth Orbit Systems}

In order to appreciate the potential benefits of a hybrid air-breathing launch-assist low Earth orbit (LEO) system (catapult-ramjet-rocket) it is necessary to perform analysis and make some elementary comparisons with an allchemical rocket system (rocket-rocket). A representative two-stage liquid-fueled all-chemical rocket system was chosen as a reference system. The comparative analysis was directed more toward an intermediate-weight launch 
system with the general philosophy that a highly repetitive system could prove to be more economical. The preliminary analysis excluded details such as dynamic pressure effects on structural weights, a ramjet engine which responds to dynamic inlet pressure, and separated fuel and oxidizer systems. The following analytical methodology was used:

1) Develop an all-chemical reference system

2) Provide first stage with high $I_{s p}(\sim 900 \mathrm{~s})$ to mimic an air-breathing stage

3) Investigate the first-stage engine arbitrarily limited to two discreet velocities: Mach 4 and Mach 10

4) Investigate the addition of launch assist in the supersonic area (Mach 1.5) to mimic ramjet ignition

5) Investigate the change of launch assist with altitude to simulate mountaintop launch.

\section{A. Gemini-Titan: A Reference All-Chemical Low Earth Orbit System}

The Gemini-Titan program was one of the most successful space programs during the Cold War. Ten missions were launched into low Earth orbit to investigate pre-Apollo orbital dynamics, and a Titan II G of similar configuration was also used as the launch system on the successful Clementine selenocartographic mission in 1994. The intercontinental ballistic missile (ICBM) -based Titan II system was selected as the reference system for this analysis because the performance of the Titan II $G$ is relatively well known, the sequence of operations is straightforward, and many parameters are well-publicized. The system can typically deliver a $\sim 8000$-lb payload into a standard orbit of $100 \mathrm{~nm}(185.2 \mathrm{~km})$ with an inclination of $28.5 \mathrm{deg}$, using a two-stage liquid-fuel rocket system.

The authors relied on several sources of Gemini-Titan data. ${ }^{9-14}$ The ten Gemini Program missions were compared and average numbers were computed to best fit the available data because of conflicting Gemini-Titan data (primarily the stage weights and onboard propellant weights). From this comparison a representative standardized 100-nm circular orbit was composed.

The Program to Optimize Simulated Trajectories (POST), provided by the NASA Langley Research Center, Hampton, Virginia, and the Lockheed Martin Corporation (Bethesda, Maryland) ${ }^{15}$, was used for the payload-to-orbit analysis estimates. Constant $I_{s p}$ modeling was used in the simulations because information regarding the Titan booster performance curves is limited and the references indicate that the first and second stages are fixed at $100 \%$ throttle. The model was developed initially without guidance and the rocket was simulated using a 90-deg flight path angle $(\gamma=90)$ in order to adjust the specific impulses to match the burnout final weights. The dynamic pressure was constrained to $950 \mathrm{psf}$ in the Gemini simulation. The second stage $I_{s p}$ in the Gemini model was typically adjusted down in order to match the final weights.

The modeled guidance and optimization mimicked the standard three-stage vehicle model distributed with the POST software package using pitch control optimization. An approximated drag curve was used. ${ }^{6}$

The rocket-rocket reference simulation will be compared to the catapult-ramjet-rocket system. The supersonic catapult is expected to boost the ramjet to efficient operational speeds. The purpose for this course of action is the assumption that the substitution of a potentially higher $I_{s p}$ catapult-ramjet booster stage will result in overall increased performance. The benefits of the coupled supersonic catapult-ramjet system will be lower system weight and reduction in vehicle complexity by the avoidance of an initial rocket system required to boost the ramjet to usable ignition pressures.

\section{B. The Hybrid Air-Breathing Launch-Assist System Simulation}

The following two subsections discuss the comparison of the reference system (rocket-rocket) to an air-breathing booster stage without launch-assist (ramjet-rocket) and with launch-assist (catapult-ramjet-rocket).

\section{Air-Breathing Booster Stage Simulations without Launch Assist}

The first-stage burnout speed attained in the previous Gemini-Titan simulations was Mach 8.725. Mach 10 air-breathing propulsion systems are currently at a very low TRL; however, in order to gain an initial understanding of the impacts of an air-breathing stage, the upper limit for the air-breathing first stage was arbitrarily set to Mach 10 for the initial simulations. In order to simulate a simple air-breathing ramjet booster, the first-stage $I_{s p}$ was changed to a reasonable ramjet $I_{s p}$ of $900 \mathrm{~s}$. The simulation was also limited to a dynamic pressure of $1500 \mathrm{psf}$.

The event at the end of the first-stage burnout was constrained by Mach number, and unconstrained first-stage Mach and dynamic pressures showed higher final payload performance. It was found that the GLOW could be reduced from the all-rocket reference system of $340,000 \mathrm{lb}$ to $165,000 \mathrm{lb}$ for the Mach 10 air-breathing booster stage. The payload performance increased by $1810 \mathrm{lb}$ (see Table 2), a 20\% increase for the Mach 10 air-breathing booster stage. Figure 2 shows a comparison of the first stage at $I_{s p}=900 \mathrm{~s}$ and reference all-chemical rocket system trajectories. But since Mach 10 air-breathing propulsion systems are currently at a low TRL, it became necessary to consider limiting the air-breathing stage to Mach 4. The Mach 4 requirement was essentially the operational usable 
thrust range of a ramjet ${ }^{6}$. The Mach 4 simulation showed that a reduction in initial GLOW $(190,000 \mathrm{lb})$ with a delivered payload of $7116 \mathrm{lb}$ can be achieved by composing a system that requires only an air-breathing Mach 4 boost, and is technologically feasible. The Mach 4 limit also places the system in a technology arena that does not impose unreasonable demands on the strength and temperature of the constructing materials.
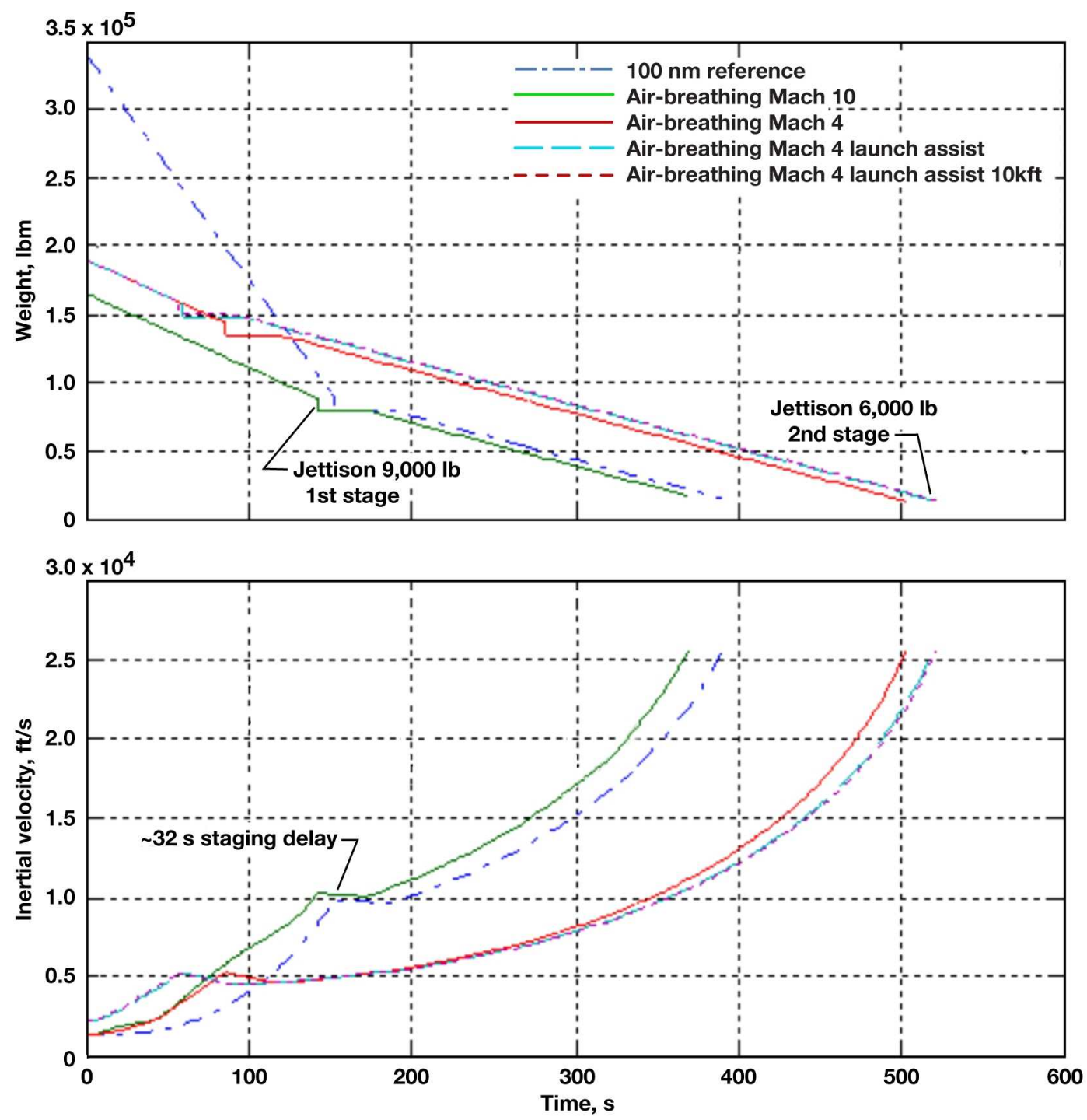

Figure 2. Comparison of air-breathing-only first stages, air-breathing with launch assist, air-breathing launch-assist from a mountaintop, and the reference all-chemical rocket system. 
Table 2. Comparison of air-breathing first stage plus launch assist and reference all-chemical rocket system. The final orbital speed $(25,570 \mathrm{ft} / \mathrm{s})$ and altitude $(607,600 \mathrm{ft})$ for all of the simulations are approximately the same. Earth's rotation (1342 ft/s) at $28.5 \mathrm{deg}$ inclination is included in first-stage inertial velocity. In all cases in this paper, the weight values are used rather than mass and the weights are calculated as though the mass is on the surface of the Earth.

\begin{tabular}{|c|c|c|c|c|c|c|c|c|}
\hline POST simulation results & GLOW & $\begin{array}{l}\text { First } \\
\text { stage }\end{array}$ & $\begin{array}{c}\text { First stage } \\
\Delta V\end{array}$ & & $\begin{array}{l}\text { Second } \\
\text { stage }\end{array}$ & & $\begin{array}{c}\text { Second } \\
\text { stage } \\
\Delta V\end{array}$ & $\begin{array}{c}\text { Final } \\
\text { payload }\end{array}$ \\
\hline & $\mathrm{lb}$ & $I_{s p}$ & $\mathrm{ft} / \mathrm{s}$ & duration & $I_{s p}$ & duration & $\mathrm{ft} / \mathrm{s}$ & $\mathrm{lb}$ \\
\hline Reference System & 340,000 & 296 & 9846 & 152 & 316 & 206 & 15,724 & 8922 \\
\hline Air-breathing to Mach 10 & 165,000 & 900 & 10,271 & 142 & 316 & 196.6 & 15,297 & 10,732 \\
\hline Air-breathing to Mach 4 & 190,000 & 900 & 5225 & 85 & 316 & 415 & 20,343 & 7116 \\
\hline $\begin{array}{l}\text { Launch assist at Mach } 1.5 \\
\text { Air-breathing to Mach } 4\end{array}$ & 190,000 & 900 & 5192 & 59 & 316 & 427 & 20,376 & 7638 \\
\hline $\begin{array}{l}\text { Launch assist at Mach } 1.5 \\
\text { Air-breathing to Mach } 4 \text { at } \\
10,000 \mathrm{ft}\end{array}$ & 190,000 & 900 & 5190 & 56 & 316 & 432 & 20,378 & 7673 \\
\hline
\end{tabular}

A variable geometry inlet would allow the ramjet to be efficient up to Mach 4. These initial concept simulations did not take into account the additional structural weight required for such inlets. The bipropellant turbo-pumps required for a liquid-fuel first stage are considered a reasonable tradeoff of system inert weight. The simulations also do not take into account the resultant system structural changes required as a result of the changes in dynamic pressure due to trajectory changes. The optimized simulations do not account for the pressure, temperature, and altitude dependency of the thrust performance of the ramjet. These limiting criteria will be the subject of future analyses.

\section{Air-Breathing Booster Stage Simulations with Launch Assist}

A conceptual simulation was performed which added an initial speed of Mach 1.5 to the air-breathing Mach 4 boost phase. The simulation showed the predictable increase in payload weight (approximately $7.3 \%$ ) compared to the non-launch-assist Mach 4 ramjet case; however, the reduction in system GLOW compared to the all-chemical rocket system (approximately $48 \%$ ) is still very significant.

Next, the possibility of a mountaintop launch was examined. The launch-assist simulation first was performed at sea level and straight up $(\gamma=90)$. Launching at Mach 1.5 resulted in a very high dynamic pressure of $3134 \mathrm{psf}$. The simulation was then moved to an elevation of $10,000 \mathrm{ft}$ above sea level and, as expected, the dynamic pressure was reduced to $2315 \mathrm{psf}$. The typical dynamic pressure operating range of a ramjet is 500 to $2000 \mathrm{psf}^{16}$, thus the movement to a higher altitude indicates some possible system advantages over a sea-level launch. Although the payload gain was only $35 \mathrm{lb}$, this still allowed for some reduction in the structure and associated structural weight needed to survive a launch. These types of system tradeoffs are left for future study.

\section{Enabling Technologies}

Based on the analysis presented in sections III and IV, it seems reasonable to continue active research in the area of air-breathing booster vehicles and launch assist. Subsections A through D below provide information for strategies and experiments that explore the current state of the art of these enabling technologies. To increase the TRL of launch assist, the primary interest is the development of a small-scale, low-cost electromagnetic accelerator, and eventually coupling it with a ramjet.

Per the recommendations from a study performed by the Center for Electromechanics, The University of Texas at Austin $^{17}$, linear synchronous motors were slightly more efficient (approximately 5\%) for this application. The linear induction motor, however, would be better suited for launch-assist application due to the potentially higher reliability as a result of reduced complexity. A review of the previous NASA launch-assist efforts ${ }^{18-20}$ indicated the following:

1) The focus was on combined levitation and propulsion.

2) When viewed from a flight-test readiness / TRL perspective, the emphasis on levitation should be reconsidered because of overall system cost, system complexity, and program survivability.

7

American Institute of Aeronautics and Astronautics 
If the ultimate goal is to maximize the kinetic energy a system can deliver, it can be reasonably argued that levitation is of a lower priority and not necessarily on a programmatic critical path. In addition, most induction linear motor designs have inherent transverse flux which can ultimately be used for a design configuration that combines levitation and propulsion. Given the above perspective, and in order to provide economical benchtop experiments that would yield meaningful data, it was concluded that the more immediate program goal of a transonic linear motor design could be attained by the elimination of the levitation requirement and by using a mechanical constraining system such as wheels or sliding metal-to-metal surfaces. The previous efforts also included highly customized linear motor designs; in the current study it was decided to concentrate on a relatively standard linear motor design and explore the high-speed physics of the standard design.

\section{A. Initial Demonstration: $60 \mathrm{~Hz}$ Double-Sided Linear Induction Motor (DSLIM)}

The $60 \mathrm{~Hz}$ commercial off the shelf (COTS) double-sided linear induction motor (DSLIM) concept was intended to raise the TRL of a component of the hybrid air-breathing launch-assist system by providing an economical benchtop linear motor demonstrator. The physics of the DSLIM could be investigated by using COTS $60 \mathrm{~Hz}$ linear motor designs commonly provided by the rollercoaster industry, combined with a COTS inverter used in the heating, ventilation, and air conditioning industry.

The following experimental equipment items were put together at Embry-Riddle Aeronautical University (Prescott, Arizona):

1) A 500-hp Mitsubishi FR-F740-05470-NA variable frequency drive, a pulse width modulated inverter

2) Power Superconductor Applications Corporation (New Castle, Pennsylvania) DSLIMs: model SF-75-1796-C, 4-pole, rated for $525 \mathrm{~V}, 60 \mathrm{~Hz}, 3$-phase, with class $\mathrm{H}$ insulation and a 72-inch long stator.

Since the time period for the acceleration was less than $2 \mathrm{~s}$, the inverter never operated in a continuous mode, and the maximum energy needed to accelerate a .25 in x 72 in 6061 aluminum plate was stored on the inverter's DC capacitor system.

Significant effort was also made toward designing and constructing a constraint system for the reaction plates. A 12-ft long catapult with a braking constraint system was constructed with the two DSLIMs (Fig. 3, right and center). The maximum speed reached was $159 \mathrm{mph}$, (Fig. 3, left), as measured by light-gates placed $\sim 4$ in apart at the end of the catapult. After a top speed determination, the $60 \mathrm{~Hz}$ linear motors were then placed on loan with the University of Arizona in Tucson for further testing. Figure 4 (left) shows the acceleration curve of the motors placed side by side with a peak at approximately $15 \mathrm{~g}$ 's with a similar total plate load. From these experiments it was determined that a COTS linear induction motor designed for $60 \mathrm{~Hz} / 60 \mathrm{mph}$ operation can be over-driven to at least twice its rated speed and that a COTS $60 \mathrm{~Hz}$ linear induction motor can be driven using a COTS pulse width modulated driver. The $60 \mathrm{~Hz}$ COTS design demonstrated a simple, economical benchtop model. In order to move the launchassist component of the hybrid air-breathing launch-assist system to a higher TRL, it is still necessary to increase the speed. In order to move toward higher speeds, two common strategies can be applied: increase the supply frequency and alter the geometry of the linear motors. Subsection B describes the progress toward increasing speed.
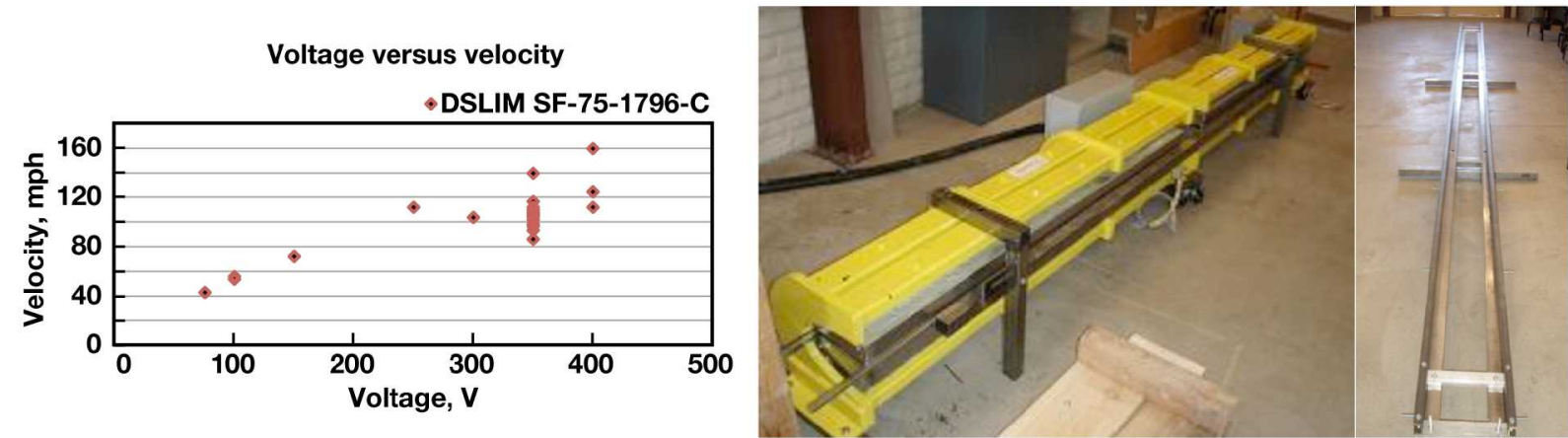

Figure 3. (Left) Experimental data showing the ultimate speed of a $60 \mathrm{~Hz}$ COTS linear motor driven with an industry standard composite square-wave variable frequency drive. (Right and center) $60 \mathrm{~Hz}$ linear motor configuration in series showing side force restraining system and free-flight travel constraining system. 

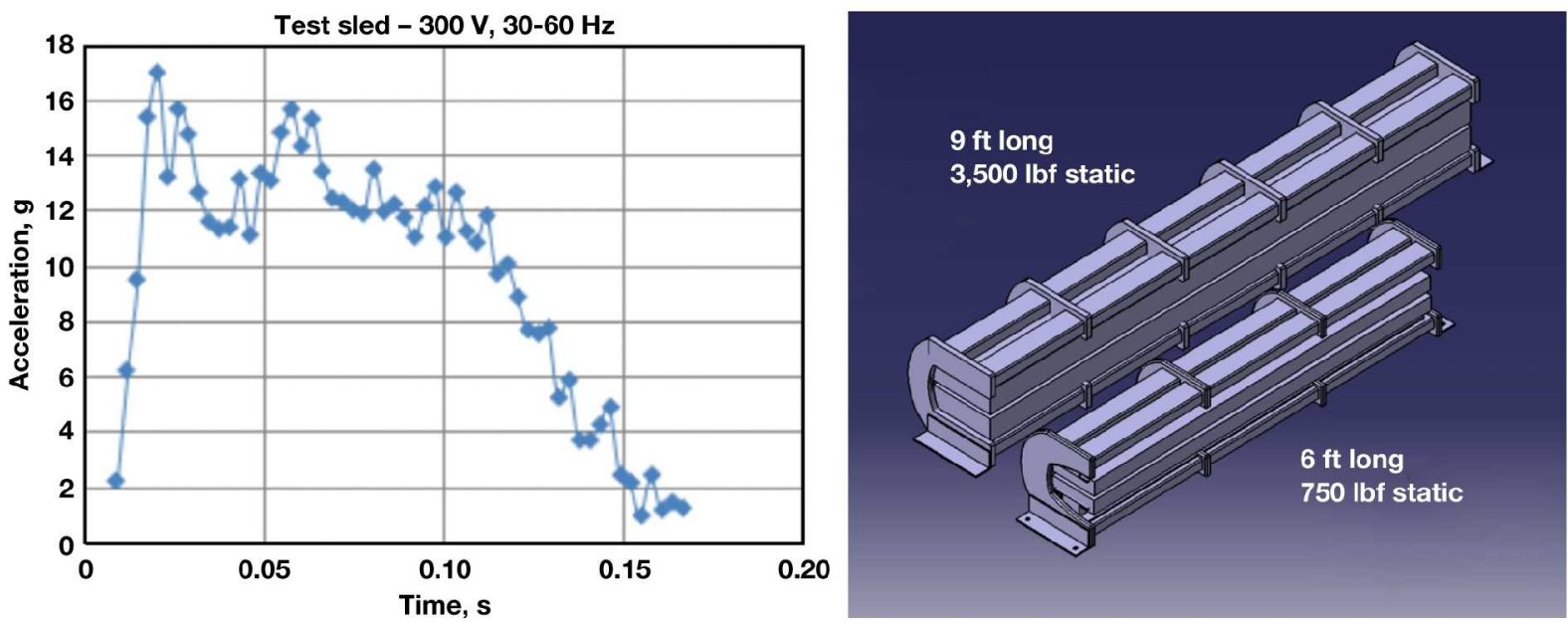

Figure 4. (Left) Experimental acceleration data from two Model SF-75-1796-C DSLIMs placed in parallel. Graph and data courtesy of Dr. Jeffrey Jacobs, University of Arizona. (Right) A side-by-side graphical comparison of the $60 \mathrm{~Hz}$ motor and the $300 \mathrm{~Hz}$ motor.

\section{B. Second Demonstration Concept: $300 \mathrm{~Hz}$ Double-Sided Linear Induction Motor}

The achievements of the $60 \mathrm{~Hz}$ COTS design indicated that an increase in speed and energy deposition could be accomplished within similar economies. Higher speed would require more power and associated specialized switching electronics. Higher speeds would also trigger the onset of high-speed linear motor entry and exit effects, which warranted consideration of a specialized design as per the second-order differential equations developed for dynamic electromagnetics in the Laithwaite and Yamamura texts ${ }^{21-23}$. General Atomics (San Diego, California) offered that it may be possible to utilize an existing 2-MW inverter at the Electromagnetics Systems Division for the next level of experimentation. To this end, a high-speed double-sided linear motor with exit-edge compensation reported by S. Kuzentsov and D. Marriott ${ }^{24}$, was provided by Power Superconductor Applications Corporation. This motor, designated Model LIM-CAT-85-2100, was a double-sided six-pole low-impedance form-wound coils linear induction catapult motor. Four motors were provided, each rated at $525 \mathrm{~V}, 300 \mathrm{~Hz}, 3$-phase operation and constructed with Class $\mathrm{H}$ insulation. Each motor utilizes 15.0 in pole pitch; a 101-inch long stator; $3300 \mathrm{lbf}$ peak output, and synchronous speed of $748 \mathrm{ft} / \mathrm{s}$ at $300 \mathrm{~Hz}$ (Figs. 5, 6). Noting that the force-speed curve of a linear induction motor is not linear, the rated output of two of the $300 \mathrm{~Hz}$ motors placed in series $(18 \mathrm{ft}$ acceleration distance) with a 30-lb load (a 10-lb reaction plate plus a 20-lb test article) should provide a end-speed of approximately $300 \mathrm{ft} / \mathrm{s}$ or $200 \mathrm{mph}$.

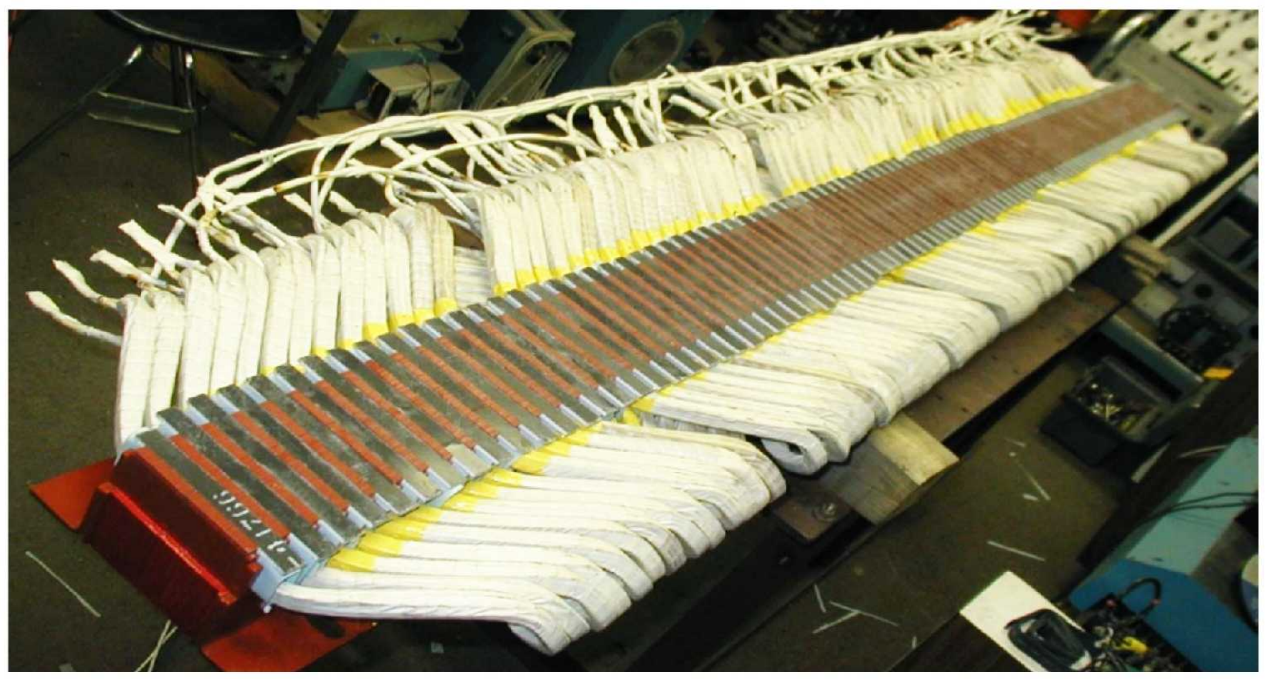

Figure 5. View of one stator of the model LIM-CAT-85-2100 DSLIM system. 


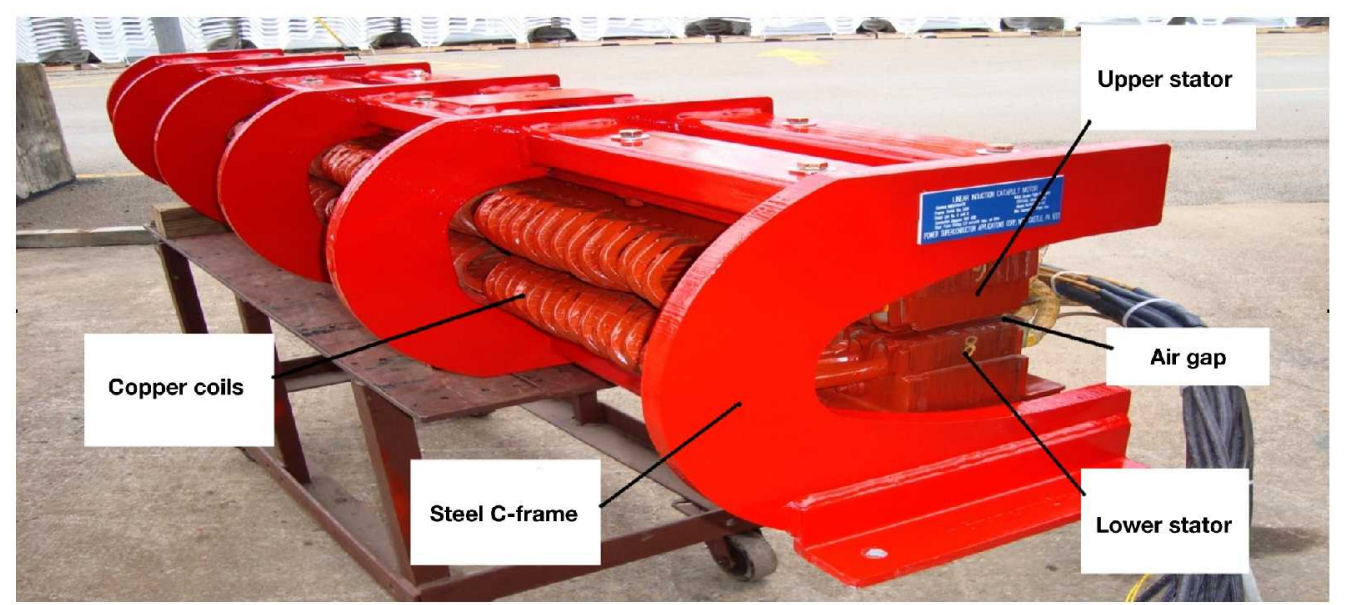

Figure 6. Completely assembled $300 \mathrm{~Hz}$ DSLIM motor, with two stators and mounted in the C-frame.

\section{Static Testing of the $300 \mathrm{~Hz}$ Double-Sided Linear Induction Motor}

The static testing of the LIM-CAT-85-2100 DSLIM's was conducted at the Power Superconductor Applications Corporation facilities. Each LIM-CAT-85-2100 DSLIM consisting of two stators and one C-frame was assembled in a test jig. Initial test data were recorded using an oscilloscope and 600:1 current transformers. Additional rigid constraint structures were constructed in and around the motor to prevent the transverse DSLIM forces from ejecting the reaction plate sideways. Based on linear induction motor theory ${ }^{21}$, it was anticipated that the sideways forces would be just as powerful as the forward intended forces. Initial tests were conducted without the reaction plate to determine no-load currents. All tests were conducted using $480 \mathrm{~V}, 60 \mathrm{~Hz}$ input power. The first no-load configuration (no reaction plate) was series-wye-connected stator windings and the recorded currents were 5 to $6 \mathrm{~A}$ per phase/motor. Next, the DSLIM stators were connected in a parallel-wye configuration. Energized individually with no reaction plate, each stator was in the 73 to $75 \mathrm{~A}$ range. Energized together they dropped to $65 \mathrm{~A}$ (the drop in current is attributed to the stators magnetizing one another).

The reaction plate was then inserted. The DSLIM air gap was measured to $.470 \mathrm{in}$, and the 5052 aluminum reaction plate was .219 in thick ( 120 in long x 24.5 in wide). The stators were configured in parallel-wye. Initially, a single stator was energized and a thrusting force was observed. Both stators were then energized together, and the steady-state current (after $1 \mathrm{~s}$ ) was in the 270-A range per stator with $1300 \mathrm{lb}$ of average thrust for the DSLIM. Peak thrust at inrush was $3000 \mathrm{lb}$. Configured in delta, the steady-state current was $300 \mathrm{~A}$ per stator and thrust was $1900 \mathrm{lb}$, while the peak thrust was $3500 \mathrm{lb}$. The energizing sequence was performed manually and therefore not synchronized with the zero-crossing of the input voltage, thus several tests were performed in order to estimate the full force due to zero-crossing synchronization. Figure 7 shows a typical thrust curve of a single stator.

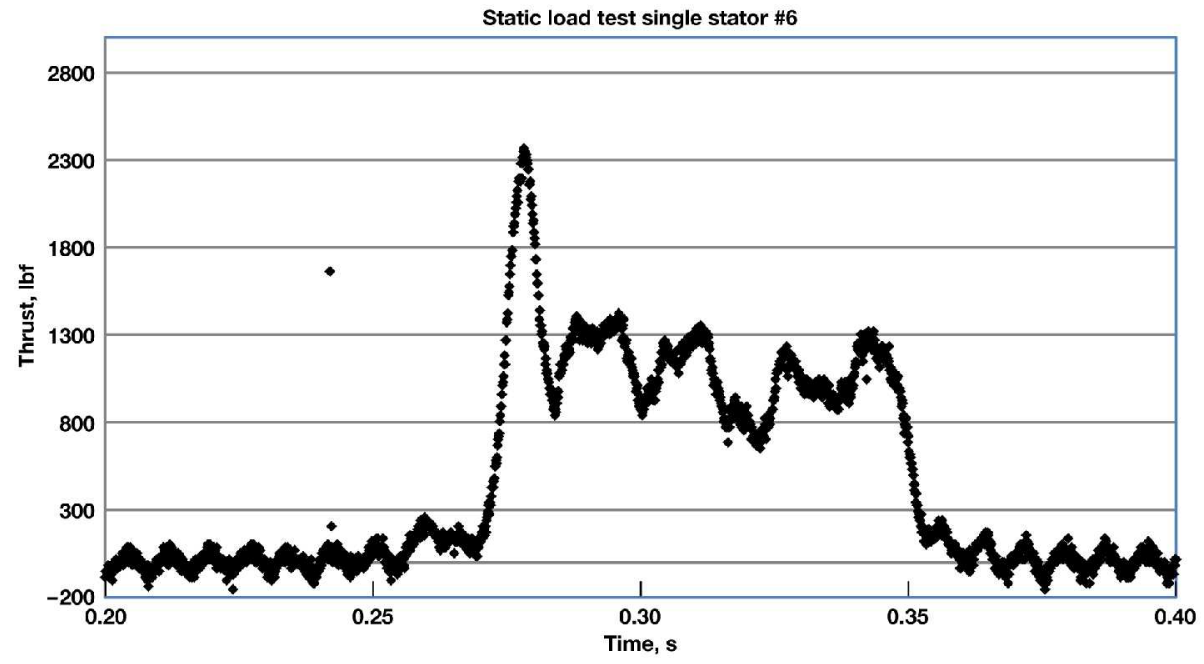

Figure 7. Static load cell testing of a single-sided stator showing peak thrust of $2300 \mathrm{lbf}$ and an average static thrust of $1167 \mathrm{lbf}$ at an applied $480 \mathrm{~V}, 60 \mathrm{~Hz}$.

American Institute of Aeronautics and Astronautics 


\section{Proposed Dynamic Testing of the $300 \mathrm{~Hz}$ Double-Sided Linear Induction Motor}

Dynamic testing of the DSLIMs will take place using the General Atomics Urban Maglev test facility in San Diego. The key system to be utilized in this facility is the inverter system that drives the Urban Maglev Test Vehicle. The Urban Maglev System is a magnetically-levitated peoplemover system design to accommodate up to 100 passengers at speeds up to $100 \mathrm{mph}$. The inverter system consists of $480 \mathrm{~V}$ AC line feeding a three-level IGBTbased inverter capable of delivering up to $11,000 \mathrm{~A}$ to a load with complete control of the inverter down to the individual switching events. The system is capable of delivering 2 MVA continuous to a load, or up to 20 MVA from the filter capacitor bank contained within the inverter. This inverter is of a similar configuration to the inverters used in the General Atomics Navy programs for aircraft launching and recovery, in which energy storage devices allow the inverters to be used at peak current and power ratings for short durations of 1 to $5 \mathrm{~s}$. Starting with and building on this inverter system will allow complete experimental flexibility in early experiments with the DSLIM, and will support testing over the full speed range envisioned for this program. Additionally, two block switches have been constructed for the later test programs which will allow operation of longer motor assemblies within the voltage limitations of the inverter and the motor windings.

The initial dynamic tests of the DSLIMs will consist of a single motor assembly connected directly to the inverters with the aluminum plate being accelerated by the motor. Figure 8 shows the setup for testing the motor system. The aluminum plate protrudes from the front of the motor, with the dark red top stator shown to be approximately half the width of the aluminum plate. Currents are generated in the center of the aluminum plate by traveling magnetic waves in the stators. Return current paths are formed in the wings of the aluminum plate on either side of the stators. The aluminum plate is guided along the length of the motor by tightly stretched plastic sheets. This approach minimizes the air gap within the motor and maximizes thrust for a given power system.
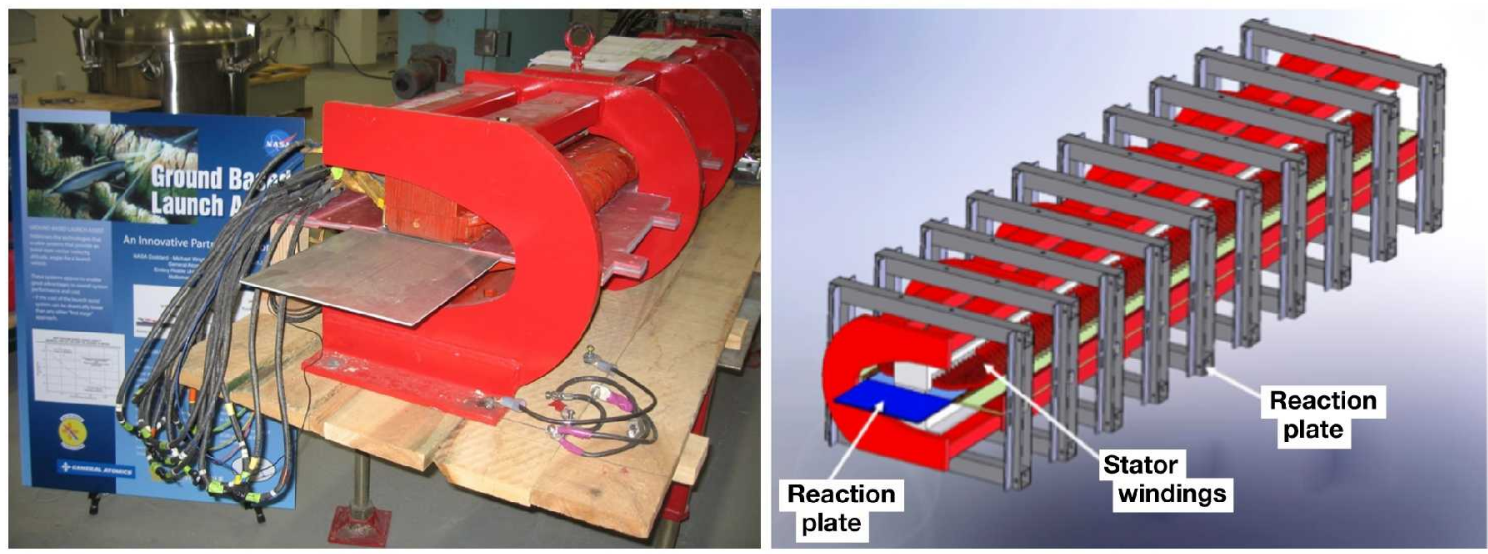

Figure 8. (Left) $300 \mathrm{~Hz}$ motor with aluminum plate in a protective micarta sleeve at the General Atomics San Diego facility. (Right) Constraint concept configuration for $300 \mathrm{~Hz}$ motor.

Testing will begin with static testing of the motor with various thicknesses of aluminum plates to characterize the slip curves for the motor for different thicknesses and conductivities. The initial dynamic testing will consist of lowspeed tests with preprogrammed current and frequency profiles. The profiles will include electromagnetic braking that will fully arrest the slow-moving plate. These tests will be used for complete system checkout and for model validation. Then, using a single motor section and a mechanical plate arresting assembly, a series of increasing velocity tests will be performed using three different aluminum plate thicknesses to fully characterize the operation of a single DSLIM section. The results of these tests will be used to validate the motor and systems models. Future follow-on testing will involve the addition of DSLIM sections 2, 3, and 4 to form a 48- $\mathrm{ft}$ long motor assembly to test acceleration of the aluminum plates up to relevant speeds for launch-assist programs (Fig. 9). The longer motor tests will require the use of the block switches to effectively shorten the motor, to minimize the required drive voltage, and achieve high-speed operation. 


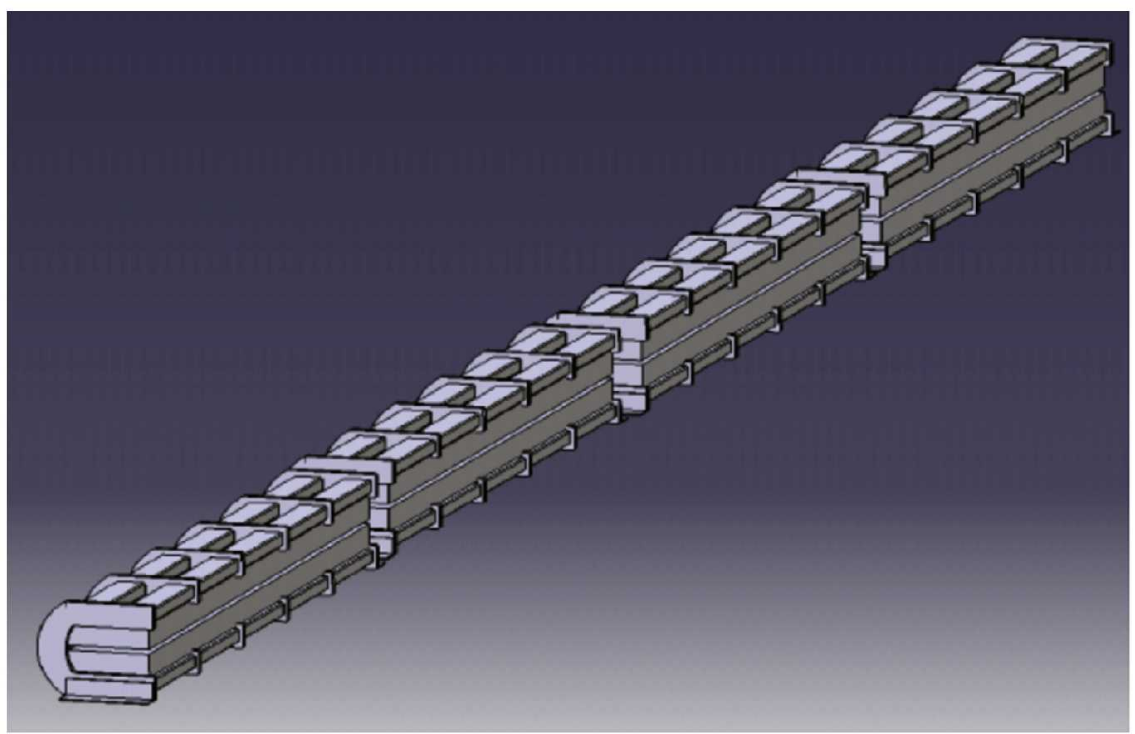

Figure 9. Conceptual configuration of four DSLIMs in series.

\section{Third Demonstration Concept: $450 \mathrm{~Hz}$ Double-Sided Linear Induction Motor Design}

The static testing results of the LIM-CAT-85-2100 DSLIM (Mk I) were encouraging, but the ultimate speed of this design does not approach supersonic. A motor capable of efficiently reaching supersonic speeds, with reduced acceleration, will probably need to be built in stages or sections. It is noted that when attempting to launch an aerospace structure, a typical limit of less than $\mathbf{5 0}$ g's should be used in the system design, therefore the terminology "reduced acceleration." Each stage of this type of high-speed linear motor should be efficient over the range of speed through which it is expected to perform, that is, a linear induction motor section designed for $300 \mathrm{~Hz}$ operation will not be as efficient when operating at $450 \mathrm{~Hz}$ as it will be when operating at $300 \mathrm{~Hz}$.

The number of stages of the catapult will depend on the final payload mass. A conceptual baseline system would have five LIM modules in tandem for a $700 \mathrm{mph}$ end speed, with the stages being progressively fed by five inverters with increasing frequency up to $450 \mathrm{~Hz}$. The LIMs will be sequentially excited in a linear frequency mode at approximately $90 \mathrm{~Hz}, 180 \mathrm{~Hz}, 270 \mathrm{~Hz}, 360 \mathrm{~Hz}$, and $450 \mathrm{~Hz}$. The baseline system design does not include electromagnetic supersonic braking, which could double the length of the track.

Thus, a high-speed LIM module (designated the Mk II) with an operating characteristic frequency of $450 \mathrm{~Hz}$ was designed by Power Superconductor Applications Corporation. This motor section is a 6-pole design and is expected to produce $4990 \mathrm{lbf}$ thrust at an approximate end-speed of $700 \mathrm{mph}$. Table 3 provides some of the basic design parameters of this Mk II LIM design. This design will have exit-edge effect and internal power factor compensation ${ }^{25,26}$. Due to the high frequency of excitation, this design will use square Litz wire of either AWG No. 8 or AWG No. 10 equivalent cross-section. This feature reduces the stator joule losses at $450 \mathrm{~Hz}$. The Mk II machine can be air-cooled by convection due to the low duty cycle. Figure 10 shows the theoretical thrust and power versus slip at $450 \mathrm{~Hz}$ input.

Table 3. Baseline design parameters for Mk II LIM launcher.

\begin{tabular}{|l|l|}
\hline Parameter & Design value \\
\hline Power output & $7.01 \mathrm{MW}$ \\
\hline Output thrust & $5,000 \mathrm{lbf}$ \\
\hline Peak force & $\sim 13,000 \mathrm{lbf}$ \\
\hline Operating slip & $8 \%$ \\
\hline Operating end speed & $1,036 \mathrm{ft} / \mathrm{s}$ or $707 \mathrm{mph}$ \\
\hline Number of stator poles & 6 per module \\
\hline Upper frequency & $450 \mathrm{~Hz}$ \\
\hline Overall length & 108 inches \\
\hline Overall width & $\sim 20$ inches \\
\hline Overall weight & $3300 \mathrm{lb}$ \\
\hline Conductor type & Square cross-section Litz wire \\
\hline Reaction plate & Aluminum 0.25 " thick, type 1100 or 6101 \\
\hline
\end{tabular}

American Institute of Aeronautics and Astronautics 


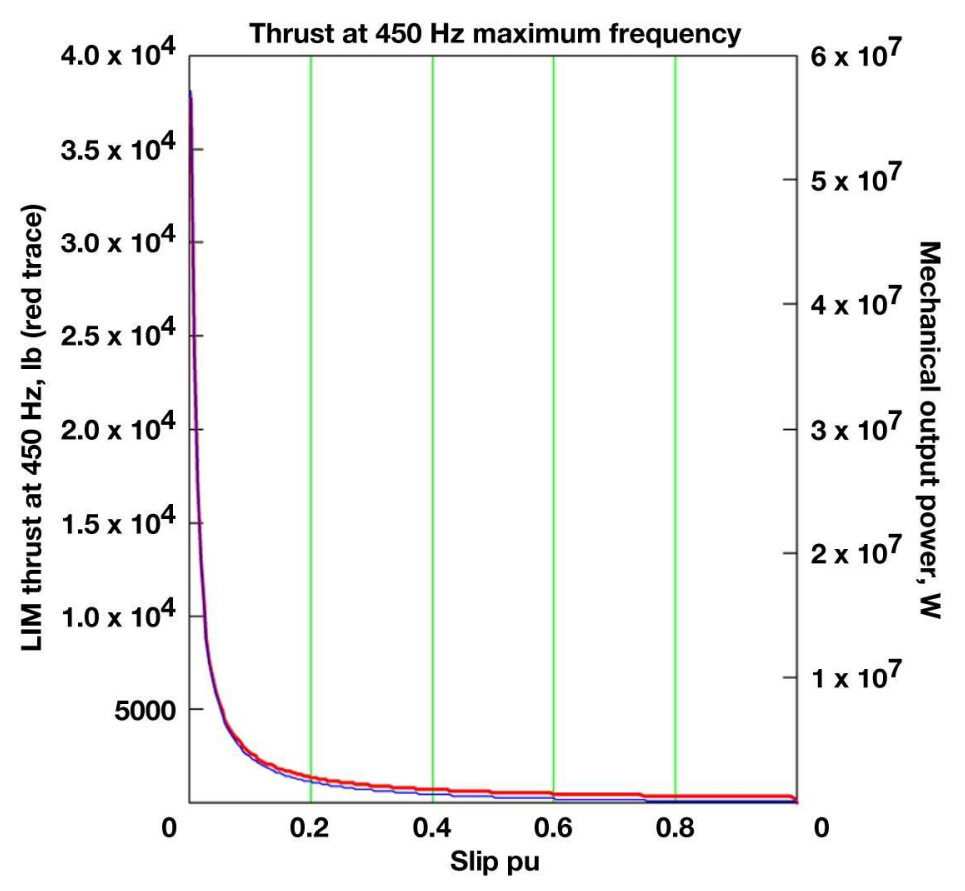

Figure 10. Theoretical performance of the $450 \mathrm{~Hz}$ DSLIM.

\section{Concept Ramjet for a Prototype Double-Sided Linear Induction Motor RAM Accelerator}

In parallel with the development of the supersonic linear motor accelerator, it is also necessary to develop a small ramjet to demonstrate that the DSLIM can effectively accelerate, ignite, and obtain thrust from a ramjet system. The development of a small ramjet will allow the system subcomponent TRL to increase and will identify critical issues such as required ignition speed and supersonic separation. In this portion of the study, Graphical Engine Cycle Analysis Tool (GECAT) (ManTech SRS Technologies, Huntsville, Alabama) engine modeling software was used to investigate different ramjet configurations and identify the potential flight envelope for a prototype system. The GECAT ${ }^{27}$, is a user-friendly software analysis tool designed and developed by SRS Technologies to assist engineers in performing air-breathing propulsion cycle design and analysis in a graphical drag-and-drop environment. The GECAT modeling was initially calibrated and verified with Stataltex ${ }^{28,29}$ and D-21 ${ }^{30,31}$ data. The following initial modeling assumptions were made:

1) Sea level to $10,000 \mathrm{ft}$ operation

2) Mach Number: 1.2 to 2

3) Burn duration: 2 to $5 \mathrm{~s}$

4) Gross wet weight: between 50 and $100 \mathrm{lb}$

5) Acceleration detection limits: 1 to $10 \mathrm{~g}$ 's out of $500 \mathrm{~g}$ 's

6) Type of fuel: JP/kerosene

From these assumptions the following initial calculations were made:

1) Acceleration: 3 to $5 \mathrm{~g}$ 's

2) Burn duration: 3 to $5 \mathrm{~s}$

3) Vlaunch_assist $=$ Mach 1.2

4) $V_{\text {final }}=$ Mach 1.6 to 1.9

5) Propellant mass fraction: $1 / 3$

6) Total ramjet weight: $20 \mathrm{lb}$

7) Net thrust: $60 \mathrm{lb}$

8) Fuel density: $50 \mathrm{lb} / \mathrm{ft}^{3}$

9) Fuel volume (JP-4): 30 to $50 \mathrm{in}^{3}$

The models were created and run at nine different on-design settings that took into account different initial velocities, combustor temperatures, operating altitudes, and inlet efficiencies. Then, these parameters and additional variables, such as mass flow rates, were varied in order to determine acceptable regions of operation. Restrictions on the models included geometries such as cross-sectional areas and a thrust requirement of a nonzero value less than 
$100 \mathrm{lb}$. From these studies performance envelopes such as that shown in Fig. 11 were developed. The conceptual envelope indicates that a small ramjet operating at Mach 1.2 can develop $60 \mathrm{lbf}$ of net thrust and would be a feasible addition to the test prototype. A typical concept modeling example would have a gross thrust of $456 \mathrm{lbf}$ and a total drag of $396 \mathrm{lbf}$ with a resultant thrust-to-drag ratio of 1.15 . The ramjet prototype would have no wings or control surfaces, and the sole purpose of such a small design would be to demonstrate ramjet ignition and thrust on an electromagnetic catapult. This would allow the development of an understanding of the operation of a combined system. Using the conceptual ramjet analysis and the progress toward the prototype supersonic accelerator, one might envision a prototype combined system experiment as depicted in Fig. 12.

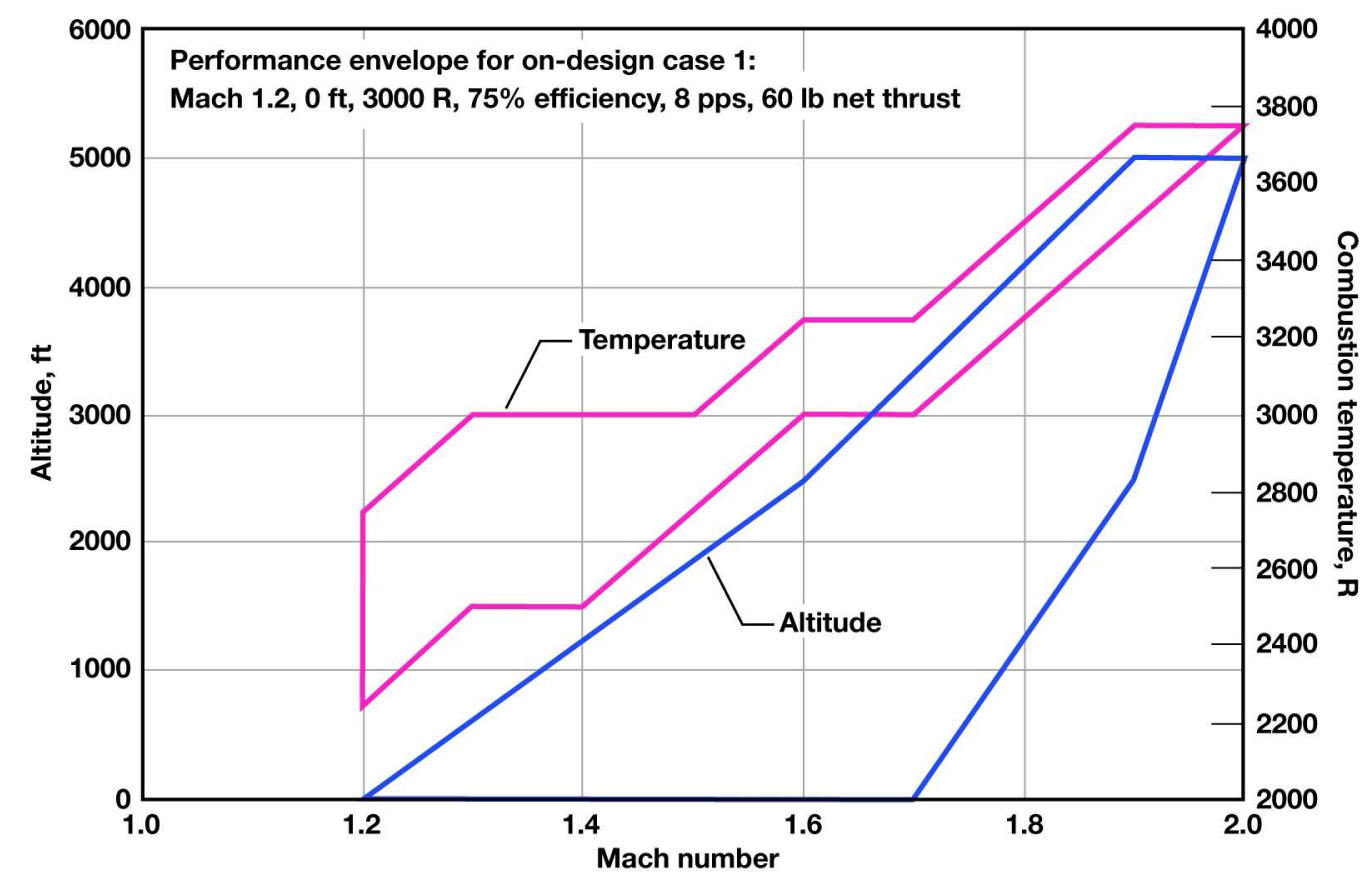

Figure 11. Performance envelope for a conceptual ramjet engine using supersonic launch-assist track.

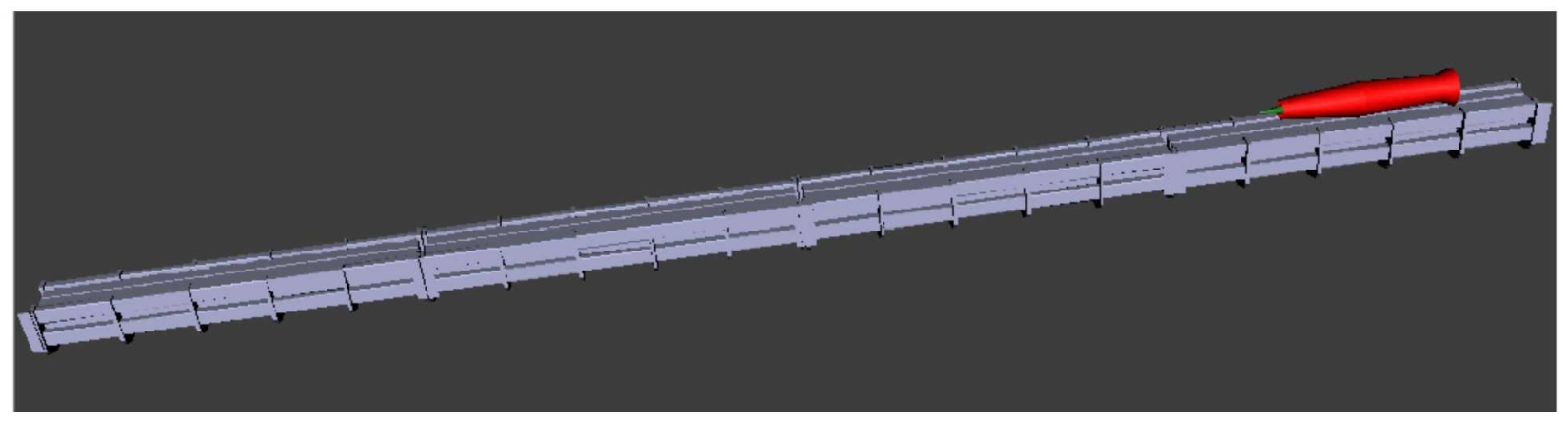

Figure 12. Conceptual ramjet engine on supersonic launch-assist track.

\section{Discussion and Conclusions}

This paper provides background analysis, initial designs, and preliminary benchtop hardware experiments that are intended to elevate the TRLs that will be required to bring an operational, full-scale air-breathing launch-assist system to fruition. Considering the ground logistics operations expenditures necessary for handling, filling, and transporting nearly $100,000 \mathrm{lb}$ of oxidizer, it seems feasible that existing ramjet technology can still produce more than adequate system performance gains relative to an all-chemical rocket system. Although the Mach 4 results are not as dramatic as those of the Mach 10 boost, the simulation results still indicate a substantial GLOW reduction. These simulations do not address the technological barrier of producing air-breathing thrust at speeds beyond Mach 4, which currently is not at a fully developed technological readiness level. The launch-assist analysis did not 
include a comparison with the possible reduction of GLOW due to air-breathing turbo-machinery or rocket-based combined cycle strategies, which could be as high as $10,000 \mathrm{lb}$ in the intermediate-weight launch systems.

The globalization of energy economies offers another shift from the Cold War mindset that originally developed orbital bipropellant technology. A brief look at the amount of terrestrial energy capital required for the final production of a bipropellant system versus a hybrid air-launch system indicates the overall energy tax on the environment should be less. This is left for future studies.

Some important conclusions of this study are as follows:

1) Analysis of suborbital solid rocket systems indicates that a supersonic launch assist can provide a $29.3 \%$ increase in Isp_virtual.

2) Trajectory analysis comparison of an non-air-breathing all-chemical rocket system with a hybrid, airbreathing launch-assist system indicates the latter can reduce the GLOW by $48 \%$ while delivering similar payload weights to a reference $100-\mathrm{nm}, 28.5-\mathrm{deg}$ inclination low earth orbit.

3) A COTS pulse width modulated inverter supplying a COTS DSLIM designed for $60 \mathrm{~Hz} / 60 \mathrm{mph}$ operation can accelerate a $10-1 \mathrm{~b}$ load up to approximately $150 \mathrm{mph}$.

\section{Accomplishments}

The effort also included hardware experimentation, which accomplished the following:

1) A unique COTS launch system was assembled that achieved $+150 \mathrm{mph} / 10 \mathrm{lb}$ to demonstrate that a relatively low-cost benchtop model could advance the TRL of launch-assist linear motors.

2) Subsequent high-speed linear motors were designed and constructed. Static load testing was performed and significant thrusting force was measured at $3500 \mathrm{lb}$ for one DSLIM.

3) Design of a higher-speed category $(450 \mathrm{~Hz})$ linear motor was completed.

4) The design of a small ramjet operating at Mach 1.2 and producing $60 \mathrm{lbf}$ of net thrust was completed for the purpose of eventually combining it with a linear motor launcher to advance the launch-assist TRL.

\section{Recommendations}

This study makes the following recommendations:

1) Continue refinement of mission analysis modeling to include ramjet dynamic pressure trajectory profile. System weight analysis should include transonic structural considerations. Study should also include comparisons to RBCC and turbo-machinery first-stage technologies. Study should consider first-stage lifting surfaces.

2) Refine ramjet design to include progressively higher thrust into the greater than $100,000 \mathrm{lbf}$ range. Ramjet design should consider variable inlet geometry or other methods of providing ramjet performance across a spectrum of Mach numbers between 1 and 4.

3) Perform a reliability study of system lifetimes, systems operations and maintenance costs, and overall capital costs. The study should also compare megaton launch vehicles to highly repetitive launch vehicles with fixed mission requirements, such as International Space Station resupply, permanent lunar presence, and Mars outpost.

4) Perform an environmental global economy system study of the over-terrestrial energy required to produce chemical systems versus hybrid air-launch systems.

5) Continue hardware testing to investigate and define ultimate speeds for linear motors.

6) Begin design of experiment for hybrid prototype Mach 1.5 ramjet with high-speed accelerator.

7) Begin conceptual designs for larger 200,000 lb Mach 1.5 linear motor accelerator.

8) Begin computational fluid dynamics studies of supersonic track interaction. Study should also provide information for track-vehicle separation studies and design of experiments for larger systems.

\section{Acknowledgments}

The authors acknowledge the following persons, without whose help this project would not have been possible: Greg Poteat, Ron Young, John Del Frate, and Ross Hathaway of the NASA Dryden Flight Research Center; Tom McCammon of the Naval Surface Warfare Center Carderock Division (NSWCCD); Mr. Douglas Comstock and Dr. Minoo Dastoor of NASA Headquarters; and Richard Hutsell and Don Ketchen of General Atomics. The authors also acknowledge the NASA Innovative Partnerships Program (IPP), the NASA Motivating Undergraduates in Science and Technology Project (MUST) and the Hispanic College Fund. 


\section{References}

${ }^{1}$ Scarlott, C.A. (ed.), “A Wound-Rotor Motor 1400 Feet Long,” The Westinghouse ENGINEER, Vol. 6, No. 5, 1946, p. 160.

${ }^{2}$ Jones, M.F., "Launching Aircraft Electrically," Aviation, Vol. 45, No. 10, 1946, p. 62.

${ }^{3}$ Doyle, M.R., Samuel, D.J., Conway, T., and Klimowski, R.R., "Electromagnetic Aircraft Launch System - EMALS" IEEE Transactions on Magnetics, Vol. 31, No. 1, 1995, pp. 528-533.

${ }^{4}$ Mankins, J.C., "The MagLifter: An Advanced Concept Using Electromagnetic Propulsion in Reducing the Cost of Space Launch," AIAA 94-2726, 1994.

${ }^{5}$ O'Neill, G.K., “The Colonization of Space," Physics Today, Sept. 1974, pp. 32-40.

${ }^{6}$ Humble, R.W., Space Propulsion Analysis and Design, $1^{\text {st }}$ ed., McGraw-Hill Primis Custom Publishing, 1995 , p. 65.

${ }^{7}$ Paris, S.W., and Hargraves, C.R., Optimal Trajectories by Implicit Simulation OTIS, Volume II - User's Manual, available from the NASA Glenn Research Center, Cleveland, Ohio 44135.

${ }^{8}$ Bui, T.T., Murray, J.E., Rogers, C.E., Bartel, S., Cesaroni, A., and Dennett, M., "Flight Research of an Aerospike Nozzle Using High Power Solid Rockets," AIAA 2005-3797, 2005.

${ }^{9}$ Isakowitz, S.J., Hopkins, J.B., and Hopkins, J.P. Jr., International Reference Guide to Space Launch Systems, $4^{\text {th }}$ ed., AIAA, Virginia, 2004.

${ }^{10}$ Ezell, L.N., NASA Historical Data Book, Volume II, Programs and Projects 1958-1968, NASA SP-4012, 1988.

${ }^{11}$ Hacker, B.C., and Grimwood, J.M., On the Shoulders of Titans, A History of Project Gemini, NASA SP-4203, 1977.

${ }^{12}$ Hacker, B.C., Grimwood, J.M., and Vorzimmer, P.J., Project Gemini, Technology and Operations, NASA SP-4002, 1969.

${ }^{13}$ Wade, M., et. al., "Encyclopedia Astronautica," http://www.astronautix.com/lvs/titan.htm, $\mathrm{http}: / / \mathrm{www} . a s t r o n a u t i x . c o m / e n g i n e s / \mathrm{lr87.htm}$, and http://www.astronautix.com/engines/lr91.htm [cited 5 August 2009 ].

${ }^{14}$ Boelling, D., http://www.titan2icbm.org/titanD.html [cited 5 August 2009].

${ }^{15}$ Brauer, G.L., Cornick, D.E., and Stevenson, R., "Capabilities and Applications of the Program to Optimize Simulated Trajectories (POST),"NASA CR-2770, 1977.

${ }^{16}$ Heiser, W.H., Pratt, D.T., Daley, D.H., and Mehta, U.B., Hypersonic Airbreathing Propulsion, AIAA Education Series, AIAA, New York, 1993.

${ }^{17}$ Caprio, M.T., and Zowarka, R.C., "MAGLEV Launch Assist Technology Demonstrator: Task 1," Center for Electromechanics, The University of Texas at Austin, Final Report to NASA Kennedy Space Center, 2001.

${ }^{18}$ Jacobs, W.A., "Magnetic Launch Assist - NASA's Vision for the Future (May 2000)," NASA Technical Reports Server Document ID 20000103883, 2000.

${ }^{19}$ Jacobs, W.A., "Magnetic Launch Assist," NASA Technical Reports Server Document ID 20000068443, presented at the 10th EML Symposium, Apr. 2000.

${ }^{20}$ Dill, J., and Meeker, D., "Maglifter Tradeoff Study and Subscale System Demonstrations," NAS-98069-1362, 2000.

${ }^{21}$ Laithwaite, E.R., Induction Machines for Special Purposes, Chemical Publishing Company, Inc., New York, 1966.

${ }^{22}$ Yamamura, S., Theory of Linear Induction Motors, $2^{\text {nd }}$ ed., John Wiley \& Sons, Inc., 1978.

${ }^{23}$ Laithwaite, E.R., and Kuznetsov, S.B., "Power-factor Improvement in Linear Induction Motors," Electric Power Applications, IEEE Proceedings B, July 1981, pp.190-194.

${ }^{24}$ Kuznetsov, S., and Marriott, D., "High Velocity Linear Induction Launcher with Exit-edge Compensation for Testing of Aerospace Components," $200814^{\text {th }}$ Symposium on Electromagnetic Launch Technology, June 2008, pp. 1-8.

16

American Institute of Aeronautics and Astronautics 
${ }^{25}$ Kuznetsov, S.B., "Method and Apparatus for Elimination of the Exit-edge Effect in High Speed Linear Induction Machines for Maglev Propulsion Systems," United States Patent No. 5,483,111, January 9, 1996.

${ }^{26}$ Kuznetsov, S.B., “Auxiliary Propulsion for Magnetically Levitated Vehicle," United States Patent No. 5,904,101, May 18, 1999.

${ }^{27}$ SRS Technologies, Inc., "GECAT Modeler with TERMAP: Visual Modeling Tool for Air Breathing Propulsion Analysis," http://www.stg.srs.com/setd/GECAT/Home.htm [cited 5 August 2009].

${ }^{28}$ Marguet, R., "Study and Flight Tests of a Mach 5 Experimental Ramjet," NASA TT F-10,319, 1966.

${ }^{29}$ McTaggart, L.E., "Feasibility of Ramjet Engine Test Capability on The Holloman AFB Sled Track," AFAPL-TR-73-80, 1973.

${ }^{30}$ Merlin, P.W., Mach 3+ NASA/USAF YF-12 Flight Research, 1969-1979, NASA SP-2001-4525, 2005.

${ }^{31}$ Merlin, P.W., From Archangel to Senior Crown: Design and Development of the Blackbird, AIAA, New York, 2008. 


\section{First Stage of a Highly Reliable Reusable Launch System}

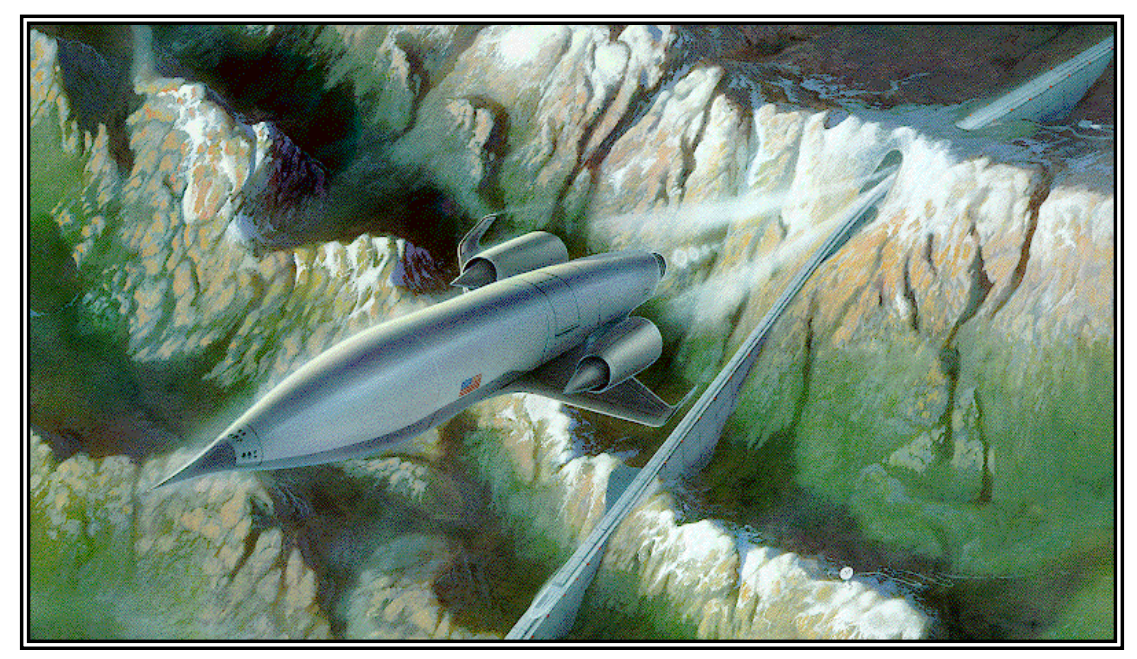

Kurt J. Kloesel, Jonathan B. Pickrel, and Emily L. Sayles

Michael Wright

Darin Marriott

Dr. Leo Holland

Dr. Stephen Kuznetsov 


\section{NASA Innovative Partnership Program}

- Kurt Kloesel, Jonathan Pickrel, NASA-Dryden

- Michael Wright, NASA-Goddard

- Emily Sayles, MUST Scholar Summer 2008, Hispanic College Fund

- Dr. Darin Marriott, Embry -Riddle Aeronautical University

- Dr. Leo Holland, General Atomics

- Dr. Stephen Kuznetsov, Power SuperConductors Applications, Inc,

ThE Hispanic College Fund Dereloging yrofessionals... one degree at a thite.

\section{EMBAY-RIDDLE AERONAUTACAL UNIVERSITY}
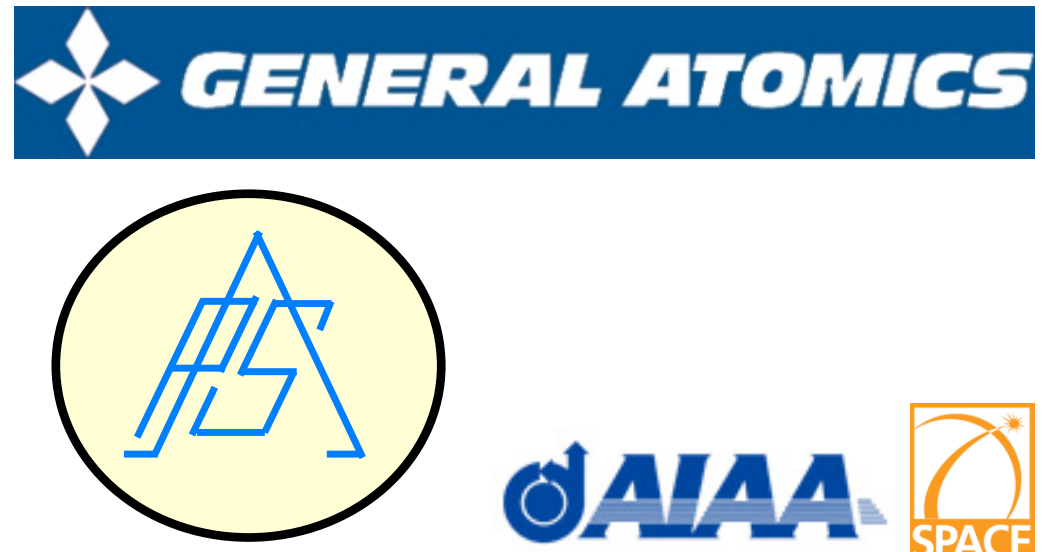


\section{Outline}

- Background / Analysis

- Virtual Isp and the Supersonic Barrier

- Gemini-Titan Reference and trajectory studies

- Hardware

- $60 \mathrm{~Hz}$ COTS Double Sided Linear Induction Motor

- 300 Hz Double Sided Linear Induction Motor

- Concepts

- Accelerator Design

- Ramjet Accelerator Concept Flight Envelope

- Summary 


\section{Catapult-Ramjet-Rocket Concept}

Ignite RAM M1.5

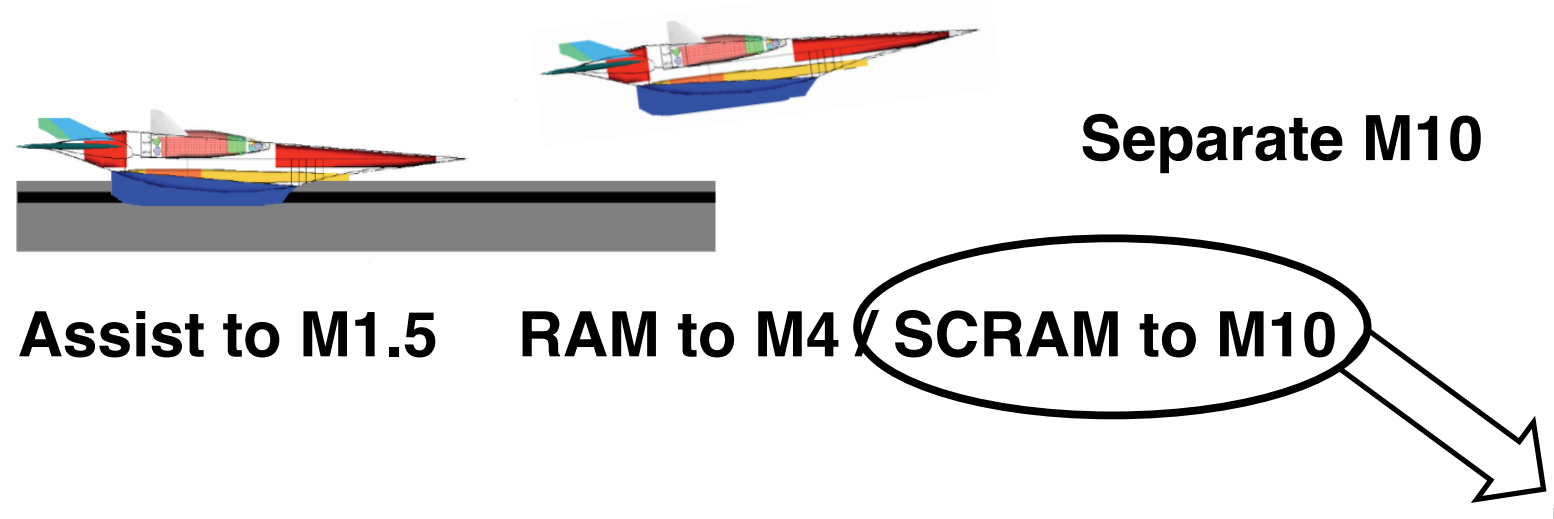

Rocket to Orbit

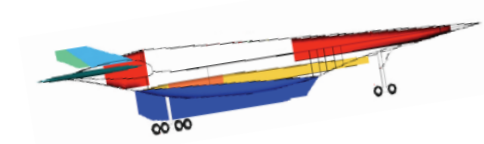

Runway Landing

Potential Gains sought:

1.) Gains in Air Breathing Stages Isp 1000s,

2.) GLOW weight reduction

3.) Gains in booster stage reliability and reusability from EM Catapult/Ramjet

4.) Existing technology - TRL's high - minimum development time/costs

5.) Provides development route for SCRAM technologies 


\section{Initial Motivation}

- Launch Energy Costs @ \$0.10 kilowatt-hour

- Superman amusement ride is 1.7MJoules \$0.50 per launch

- EMALS is about $100 \mathrm{MJ}$

\$2.77 per launch

$-200,000 \mathrm{lbs}$ at Mach 1.5 = 1.125 GJ

$\$ 31.25$ per launch! 


\section{Carbon Footprint}

\section{Chemical Propellants:}

Production

LOX - Liquefying Air (MWe)

LH2 - Compressing (MWe)

PerChlorates - Electrolysis (MWe)

Aluminum Powder - (MWe)

Transportation

Trucking Cryogenics

Barges for SRB's

Cryogenic System Maintenance

System Losses

\section{EM Propellant:}

Production

Power Plants

Requires Capital

Transportation

Distribution Lines

Grid

Storage

Rotating EM Storage

Requires Capital

Storage

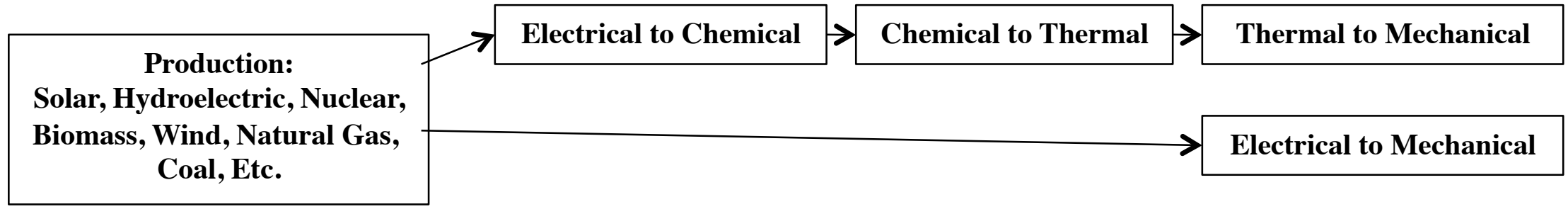

Because of accumulated system inefficiencies, Ultimate $\mathrm{CO} 2$ Release is greater for chemical propellants? 


\section{Background}

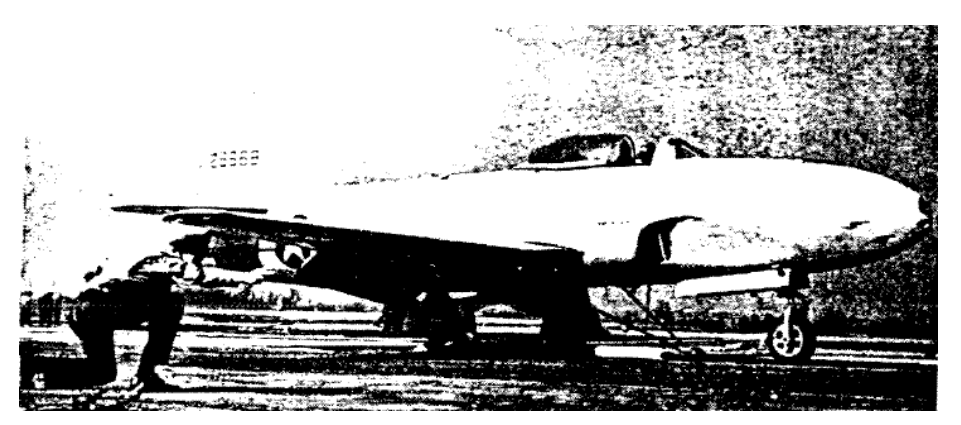

Past - 1946 Electropult

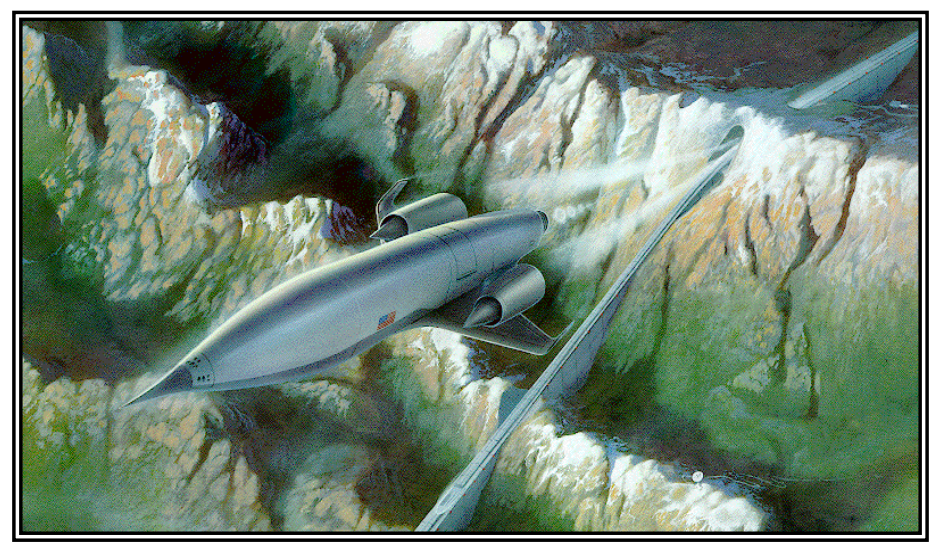

Future - Terrestrial Launch Assist

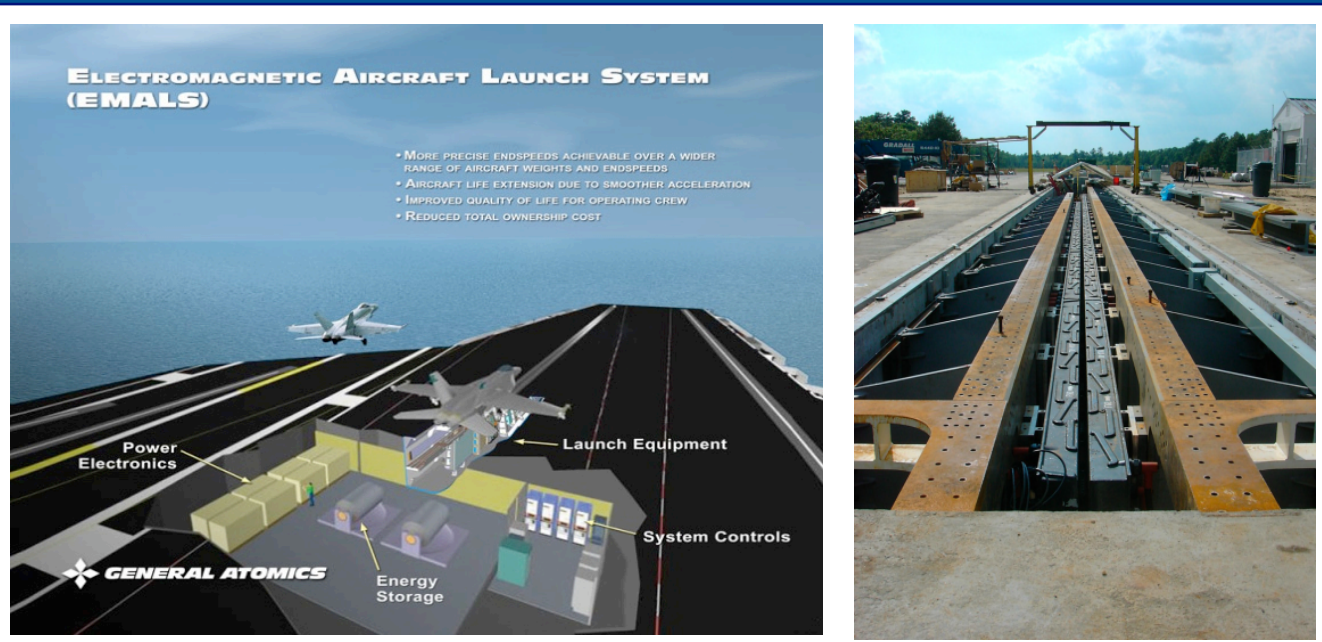

Present - EMALS

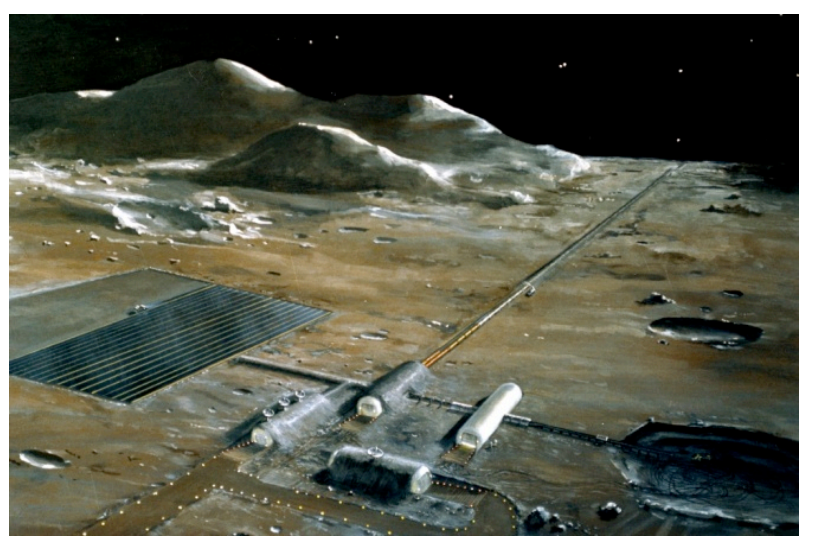

Future Future - Lunar Launch Assist

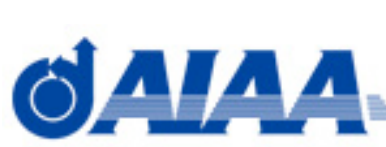




\section{Outline}

- Background/Analysis

- Virtual Isp and the Supersonic Barrier

- Gemini-Titan Reference and trajectory studies

- Hardware

- 60 Hz COTS Double Sided Linear Induction Motor

- 300 Hz Double Sided Linear Induction Motor

- Concepts

- Accelerator Design

- Ramjet Accelerator Concept Flight Envelope

- Summary 


\section{Virtual Specific Impulse}

The method of virtual specific impulse ( $\left.I_{s p \_v i r t u a l}\right)$

- developed to highlight the potential gains of a ground-based launch-assist system compared to an all-chemical rocket system.

$$
\Delta V_{\text {system }}+\Delta V_{\text {launch_assist }}-\Delta V_{\text {drag }}-\Delta V_{\text {gravity }}=g_{o} I_{s p_{-} \text {virtual }}
$$




\section{Virtual Specific Impulse Results}

\begin{tabular}{|l|l|l|c|l|}
\hline Case & Drag & \multicolumn{1}{|c|}{ Vlaunch_assist, ft/s } & Isp_virtual, s & $\%$ increase \\
\hline 1 & Vacuum & 0 & 225 & 0 \\
\hline 2 & Vacuum & $440(300 \mathrm{mph})$ & 265 & 17.8 \\
\hline 3 & Vacuum & $880(600 \mathrm{mph})$ & 306 & 36 \\
\hline 4 & Vacuum & $1563(\mathrm{Mach} 1.4 \mathrm{STP})$ & 390 & 73.3 \\
\hline 5 & Atmospheric & 0 & 215 & 0 \\
\hline 6 & Atmospheric & $440(300 \mathrm{mph})$ & 227 & 5.6 \\
\hline 7 & Atmospheric & $880(600 \mathrm{mph})$ & 248 & 15.3 \\
\hline 8 & Atmospheric & $1563(\mathrm{Mach} 1.4 \mathrm{STP})$ & 278 & 29.3 \\
\hline
\end{tabular}

Two Schools of thought

- Space: Vacuum

- Aeronautics: Drag 


\section{Transonic Drag Barrier}

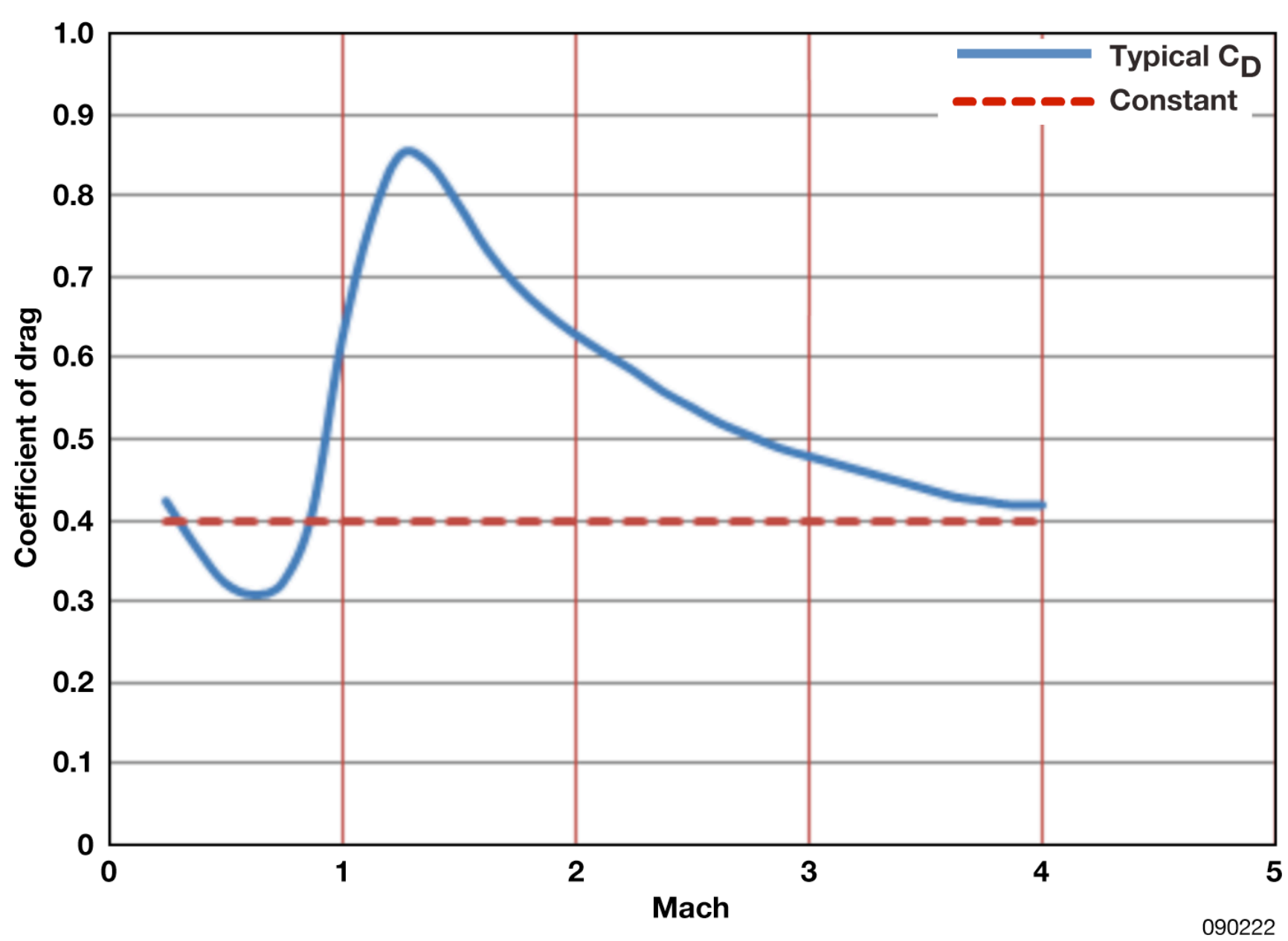

Hypothetical leveling of the drag profile provides an increase of $13 \%$ in virtual specific impulse 


\section{Gemini-Titan Reference 100 n.mile orbit}

Need a standard system to reference air-breathing launch assist simulations

A typical Gemini mission was $86 \mathrm{~nm}$ X $140 \mathrm{~nm}, .008$ eccentricity.

The reference system was normalized to $100 \mathrm{~nm}$ circular

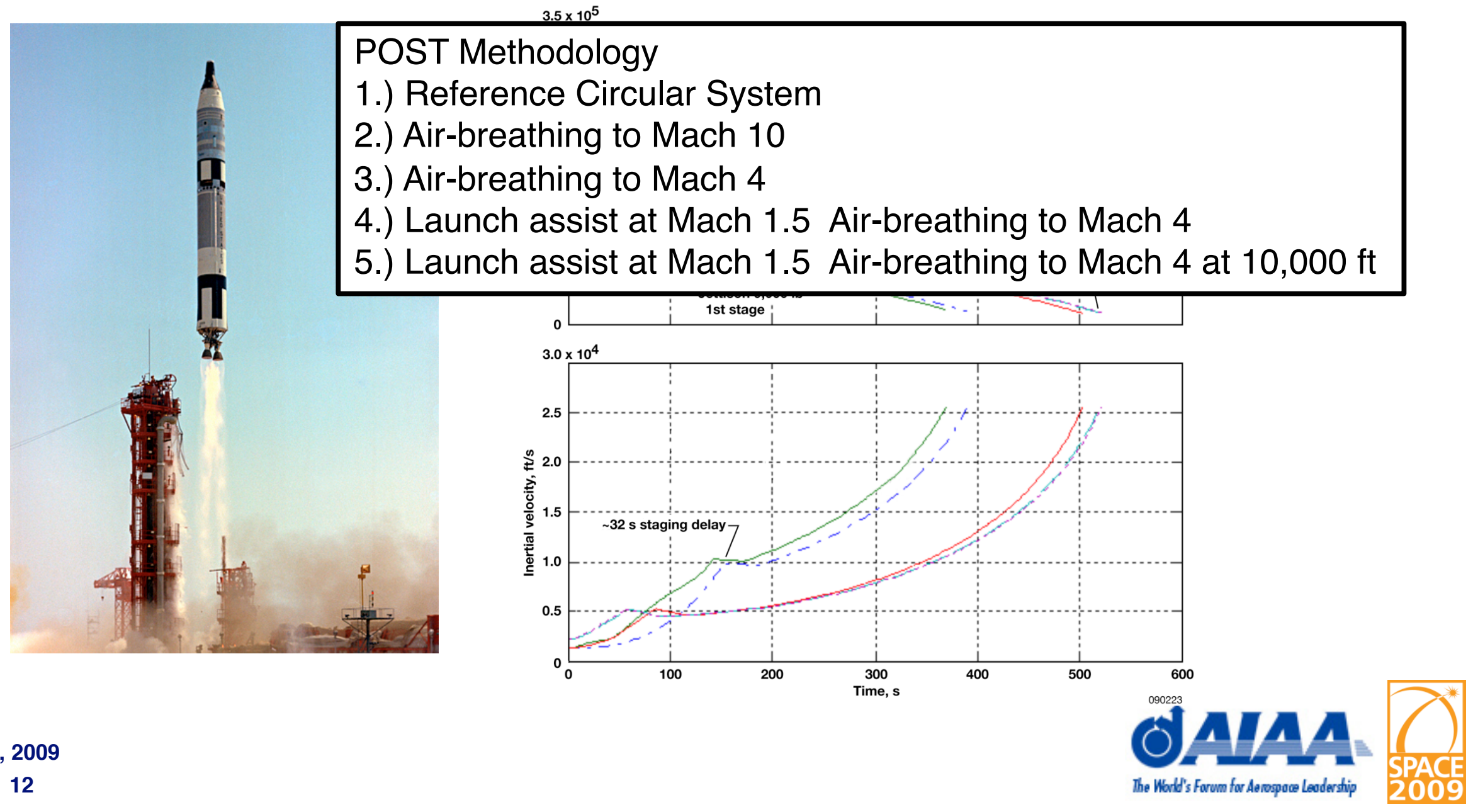




\section{POST Trajectory Analysis Results}

\begin{tabular}{|l|c|c|c|c|c|c|c|c|}
\hline POST simulation results & GLOW & $\begin{array}{c}\text { First } \\
\text { stage }\end{array}$ & First stage & & $\begin{array}{c}\text { Second } \\
\text { stage }\end{array}$ & & $\begin{array}{c}\text { Second } \\
\text { stage }\end{array}$ & $\begin{array}{c}\text { Final } \\
\text { payload }\end{array}$ \\
\hline & $1 \mathrm{~b}$ & & $\mathrm{ft} / \mathrm{s}$ & duration & & duration & $\mathrm{ft} / \mathrm{s}$ & $1 \mathrm{~b}$ \\
\hline Reference System & 340,000 & 296 & 9846 & 152 & 316 & 206 & 15,724 & 8922 \\
\hline Air-breathing to Mach 10 & 165,000 & 900 & 10,271 & 142 & 316 & 196.6 & 15,297 & 10,732 \\
\hline Air-breathing to Mach 4 & 190,000 & 900 & 5225 & 85 & 316 & 415 & 20,343 & 7116 \\
\hline $\begin{array}{l}\text { Launch assist at Mach } \\
\begin{array}{l}1.5 \text { Air-breathing to } \\
\text { Mach 4 }\end{array}\end{array}$ & 190,000 & 900 & 5192 & 59 & 316 & 427 & 20,376 & 7638 \\
\hline $\begin{array}{l}\text { Launch assist at Mach } \\
\begin{array}{l}\text { Lair-breathing to } \\
\text { Mach 4 at 10,000 ft }\end{array}\end{array}$ & 190,000 & 900 & 5190 & 56 & 316 & 432 & 20,378 & 7673 \\
\hline
\end{tabular}




\section{Analysis Results}

\section{8\% Reduction in GLOW :}

Reference 340,000 lb, 100-nm, 28.5-deg inclination LEO

\section{Dynamic Pressure Reduction from 10 kft initial launch}

-Sea-Level - 3134 psf

$\cdot 10,000 \mathrm{ft}-2315 \mathrm{psf}$

-Practical operating range for RAMJET - 500 to 2000 psf 


\section{Outline}

- Background/Analysis

- Virtual Isp and the Supersonic Barrier

- Gemini-Titan Reference and trajectory studies

- Hardware

- $60 \mathrm{~Hz}$ COTS Double Sided Linear Induction Motor

- 300 Hz Double Sided Linear Induction Motor

- Concepts

- Accelerator Design

- Ramjet Accelerator Concept Flight Envelope

- Summary 


\section{Previous NASA Linear Motor Research MSFC \& KSC Circa 2000}

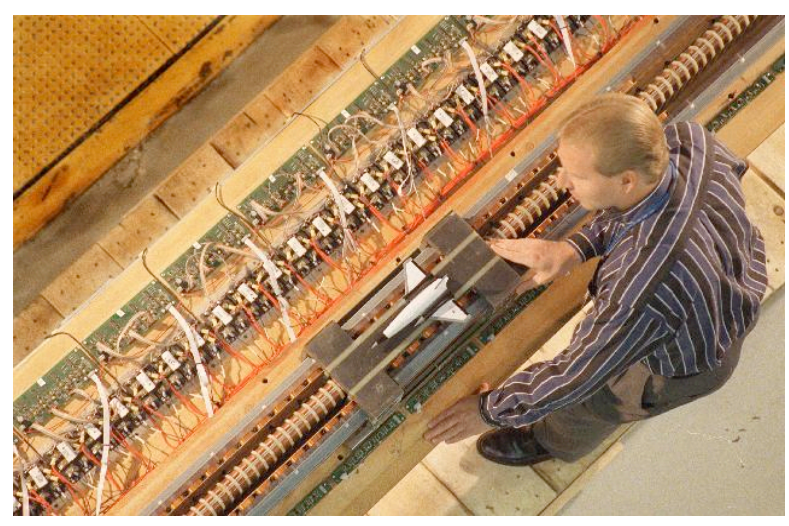

FM Track

\section{Propulsion/Levitation}

12 meter

$26.3 \mathrm{~m} / \mathrm{s}$

$6 \mathrm{~kg}$

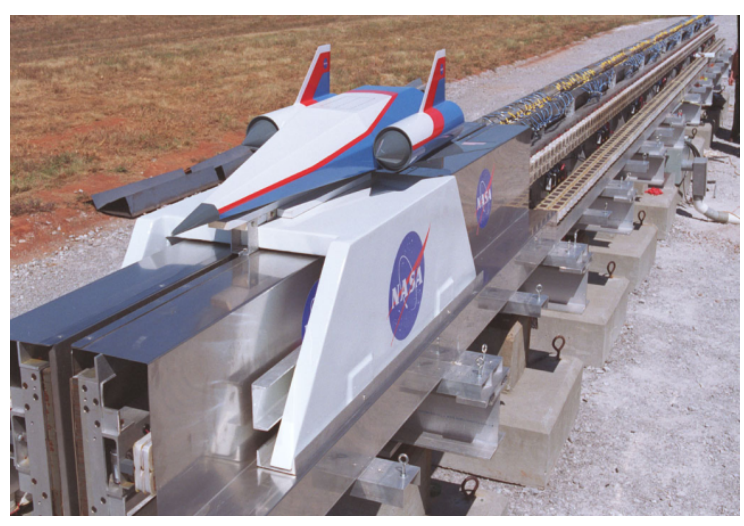

PRT Track

Propulsion/Levitation 30 meter $12.5 \mathrm{~m} / \mathrm{s}$ $58 \mathrm{~kg}$

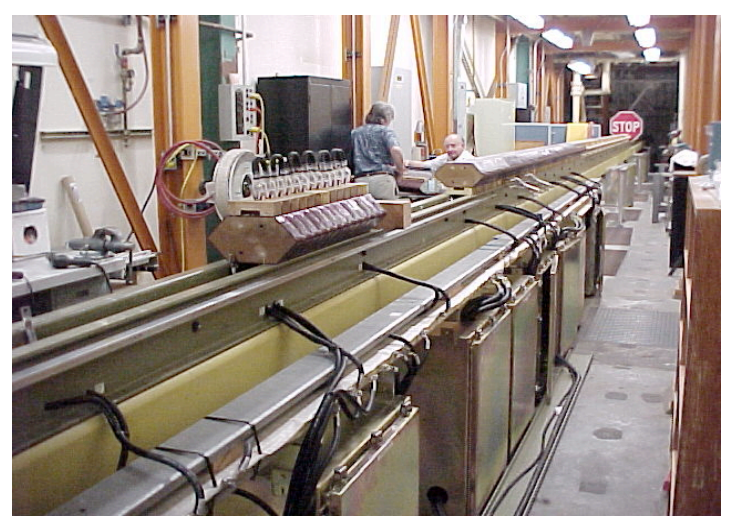

LNLL Track

Levitation 20 meter $11.9 \mathrm{~m} / \mathrm{s}$ $20 \mathrm{~kg}$

\section{Emphasis was placed on combined levitation and propulsion}




\section{Double Sided Linear Induction Motor (DSLIM)}

\section{COTS Linear Motor from Roller Coaster Industry}
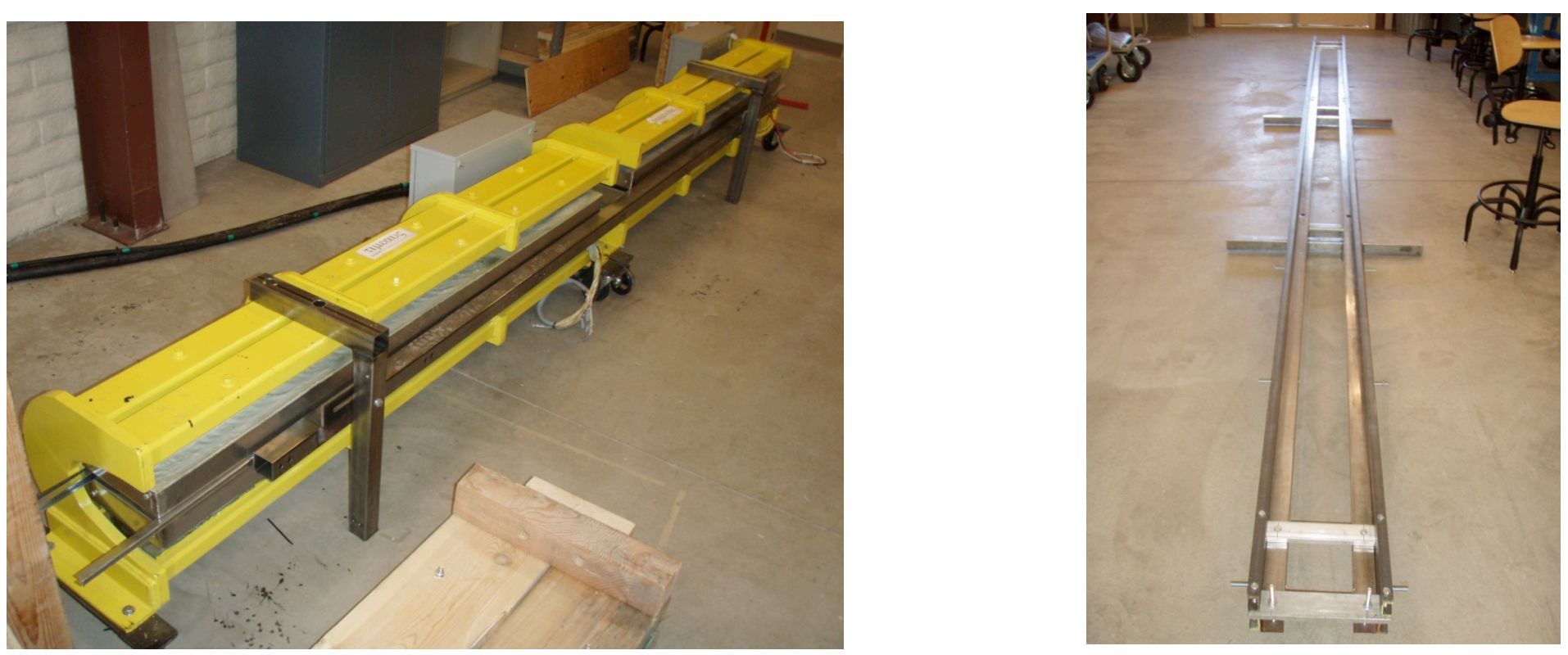

$60 \mathrm{mph}-60 \mathrm{~Hz}$ design speed / 750 lbf static force

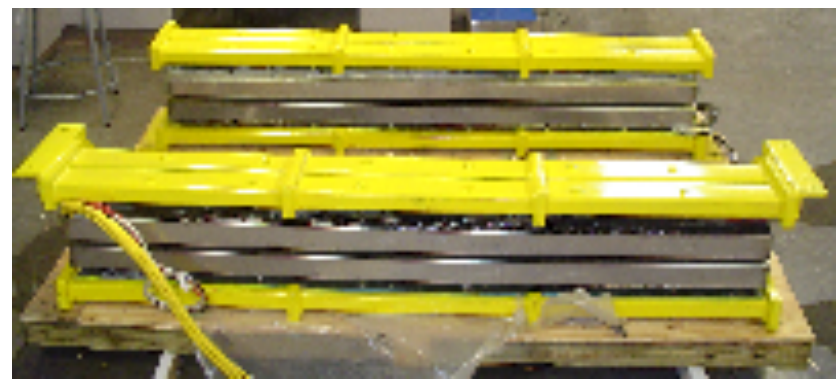




\section{Hz/500 HP Variable Frequency Inverter}

\section{COTS PWM Inverter from HVAC Industry}
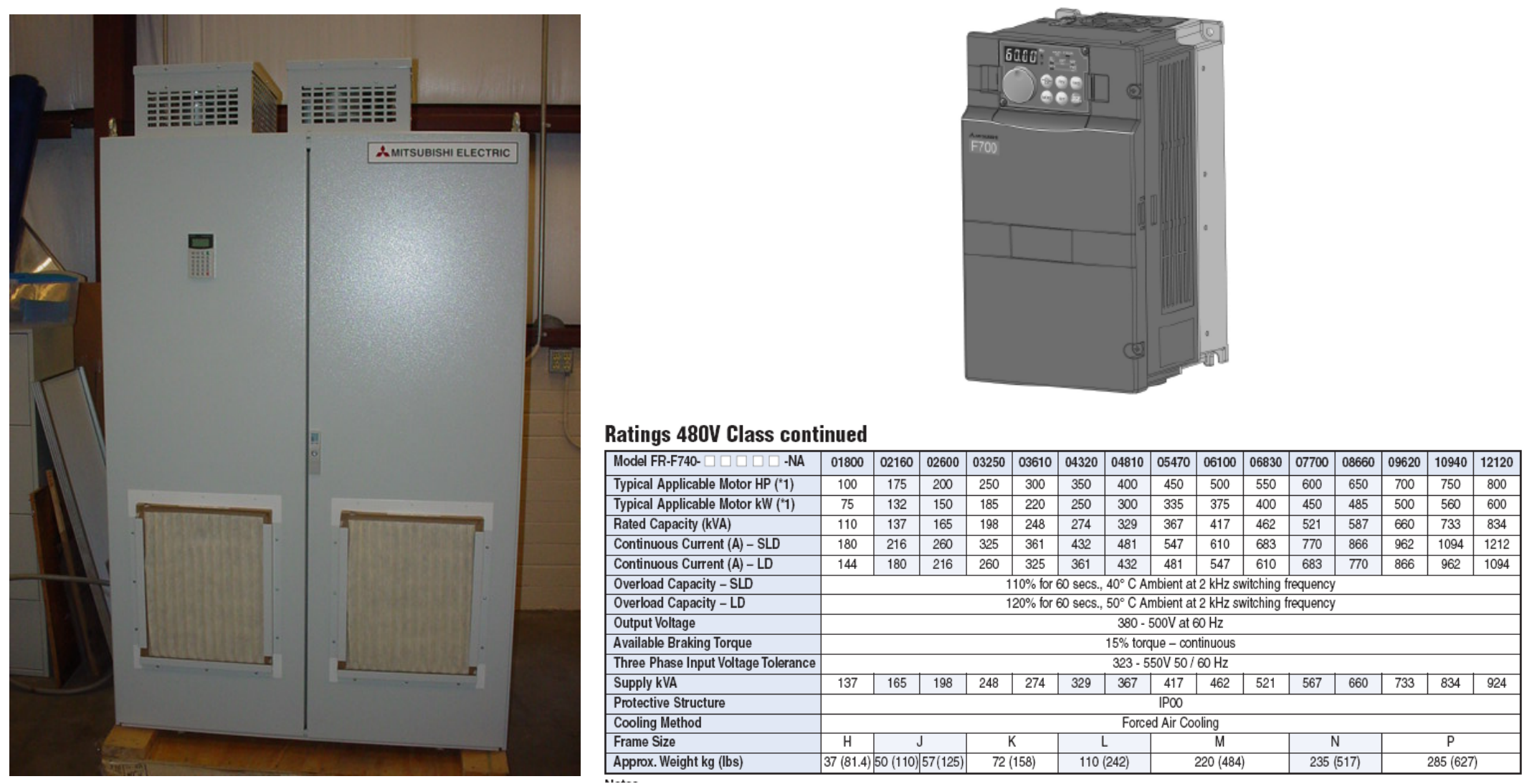

-Mitsubishi FR-F740-6100 variable frequency drive (0 to $150 \mathrm{~Hz})$ 


\section{DSLIM SF-75-1796-C Testing Results - Speed}

\section{Dryden/Goddard}

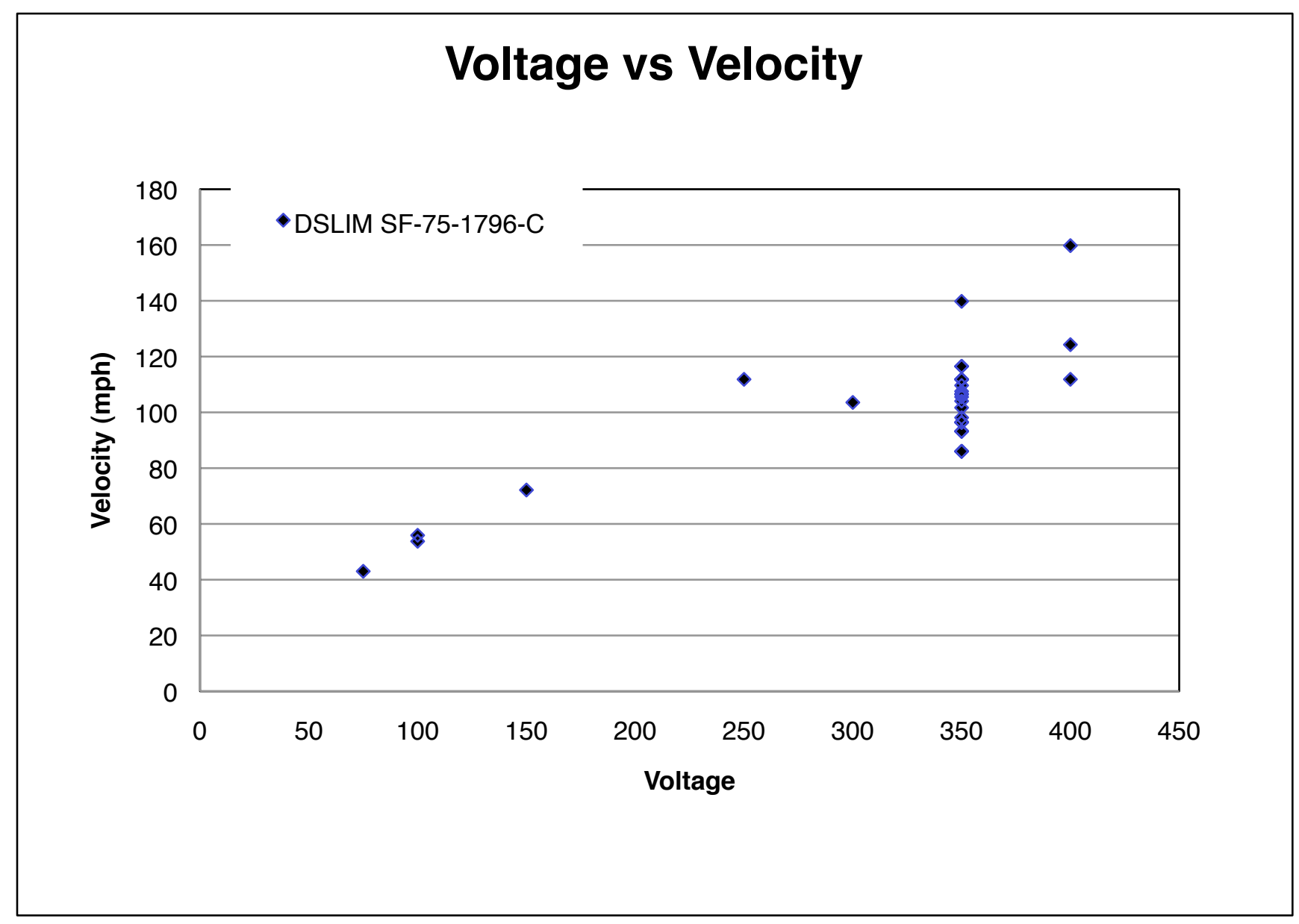




\section{DSLIM SF-75-1796-C Testing Results - Video}

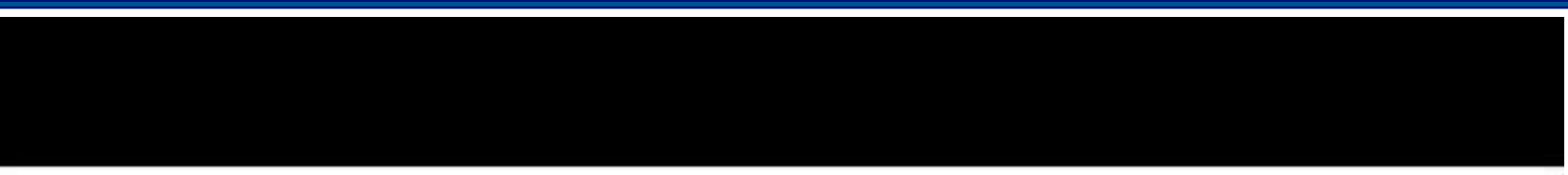

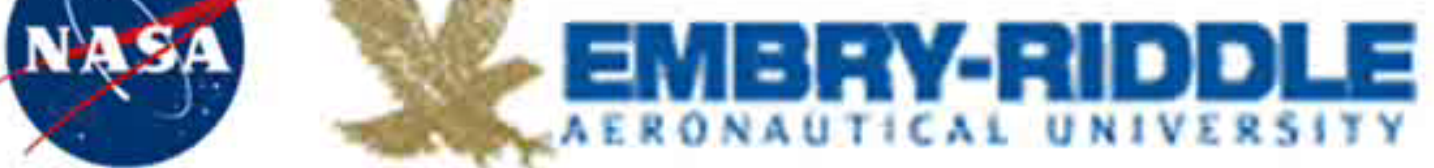

COTS Linear Motor Test

159 MPH @ 60 g's

February 2008 


\section{EM launched Solid Rocket - Plaster City Test}

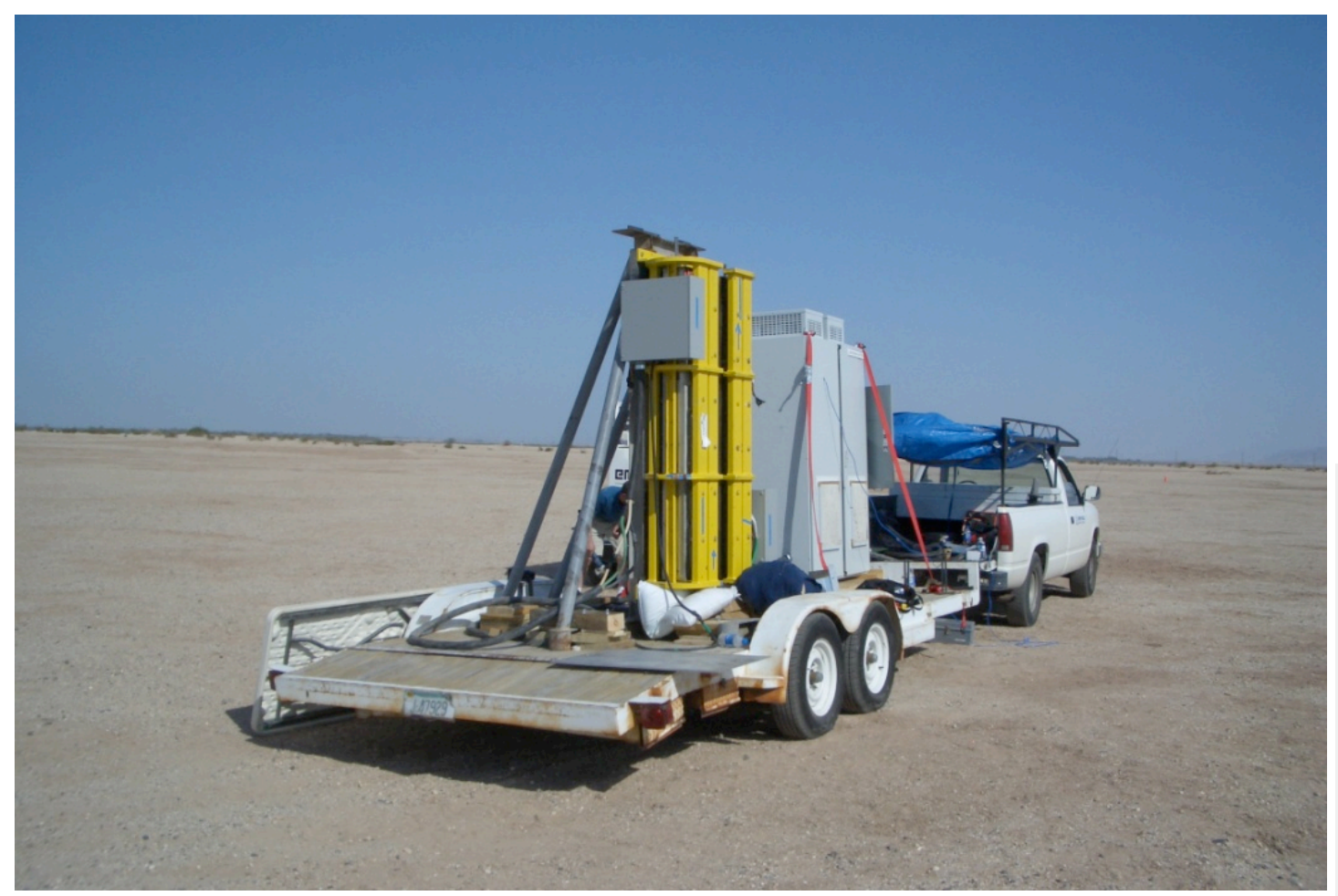




\section{IPP Spin-Off Benefit}

Test Sled - 300 Volts $30-60 \mathrm{~Hz}$
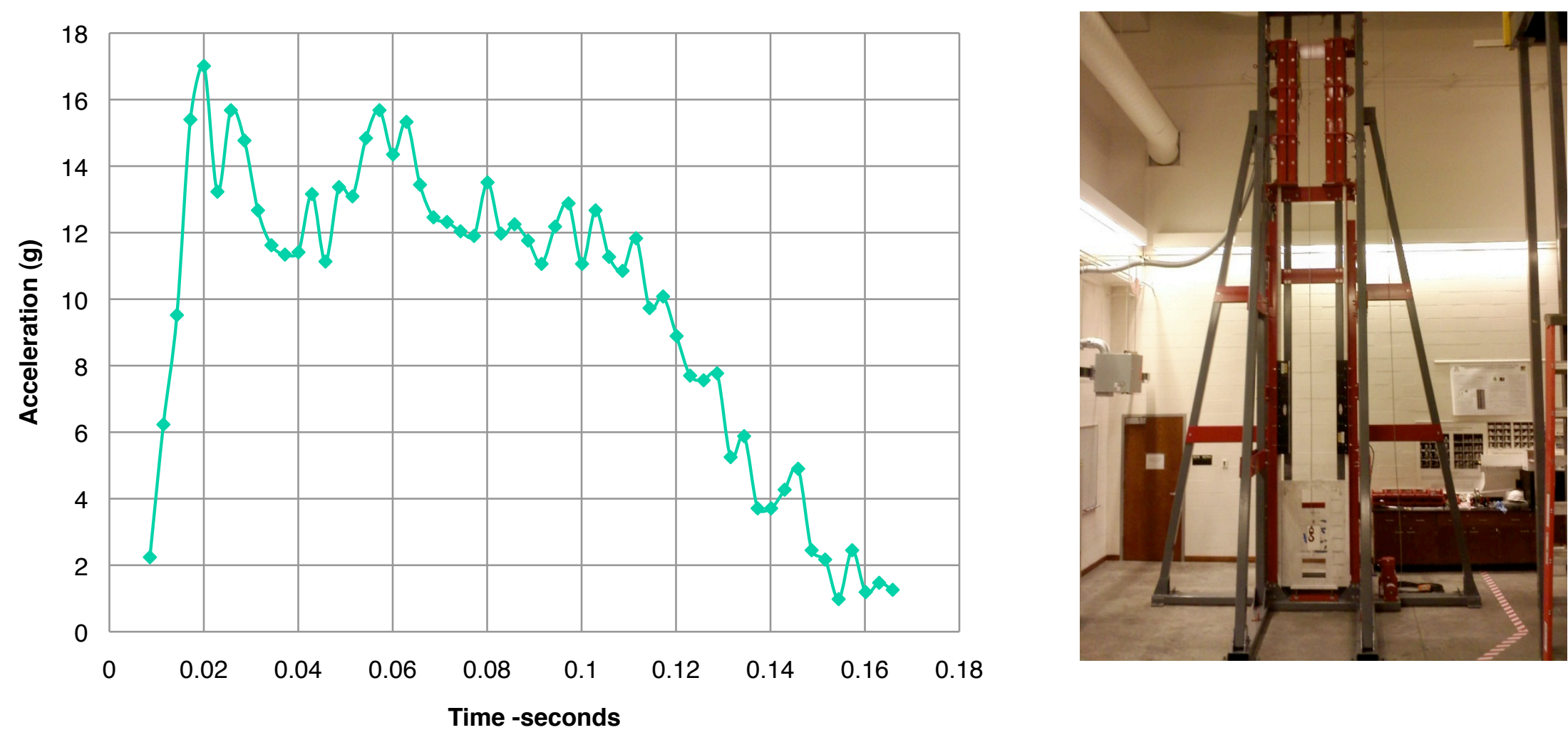

Experimental acceleration data from two Model SF-75-1796-C DSLIMs placed in parallel. Graph and data courtesy of Dr. Jeffrey Jacobs, University of Arizona. Rayleigh-Taylor CFD Studies 


\section{Launch Assist Linear Motor Progress}

\begin{tabular}{|l|c|c|c|c|}
\hline Description & \multicolumn{1}{|l|}{$\begin{array}{l}\text { Mass } \\
(\mathbf{k g})\end{array}$} & $\begin{array}{l}\text { Velocity } \\
(\mathbf{m} / \mathbf{s})\end{array}$ & $\begin{array}{l}\text { Energy } \\
\text { (Joules) }\end{array}$ & $\mathbf{\$ \$} \mathbf{\text { JJoules }}$ \\
\hline LLNL track & 20 & 11.9 & $1.42 \mathrm{KJ}$ & 701 \\
\hline FM track & 6 & 26.3 & $2.07 \mathrm{KJ}$ & 482 \\
\hline PRT track & 58 & 12.5 & $4.53 \mathrm{KJ}$ & 220 \\
\hline $\begin{array}{l}\text { Embry-Riddle } \\
\text { track }\end{array}$ & 4.67 & 71 & $11.77 \mathrm{KJ}$ & 8.5 \\
\hline $\begin{array}{l}\text { Superman } \\
\text { Amusement }\end{array}$ & 4989 & 26.8 & $1.7 \mathrm{MJ}$ & 10.5 \\
\hline EMALS & 50000 & 100 & $100 \mathrm{MJ}$ & 2.0 \\
\hline Needed & 90000 & 500 & $1.125 \mathrm{GJ}$ & $\sim 1.0$ or less \\
\hline
\end{tabular}




\section{High Frequencies/Motor Geometry $\sim$ Speed \\ LIM-CAT-85-2100 DSLIM}

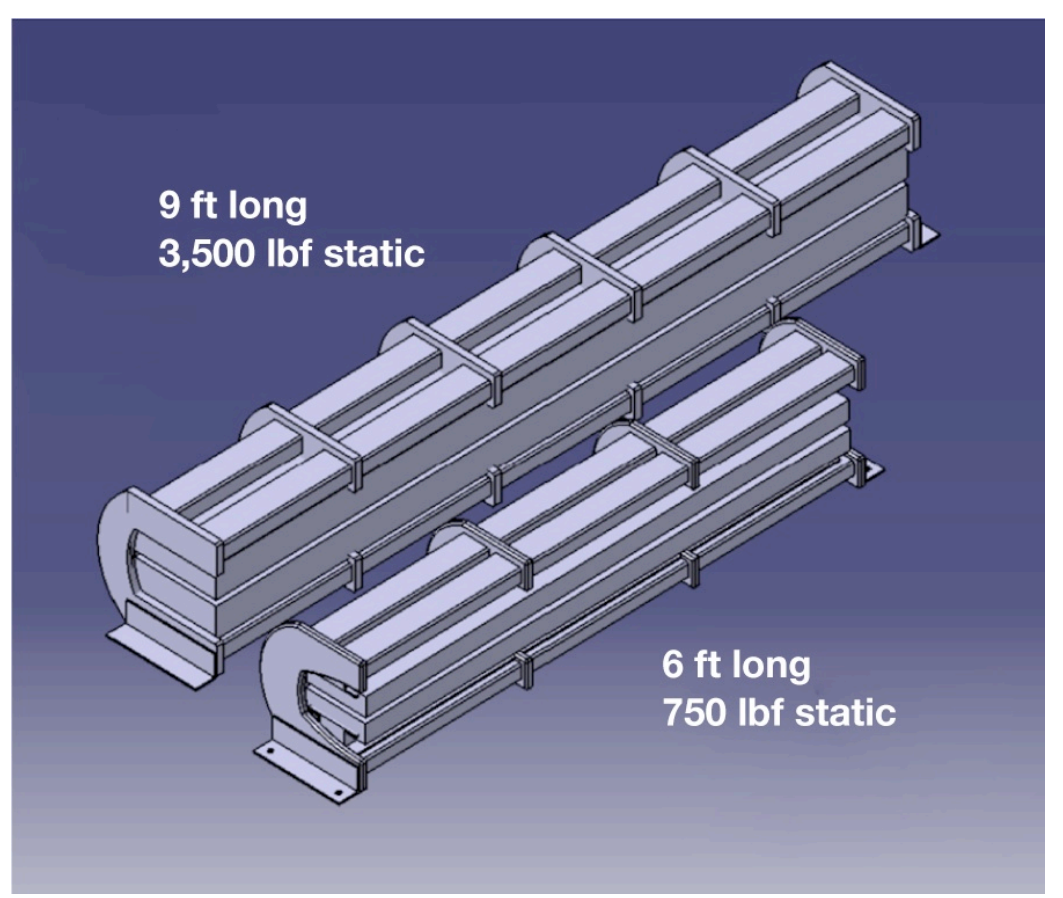

Graphical comparison of the 60 $\mathrm{Hz}$ motor and the $300 \mathrm{~Hz}$ motor.
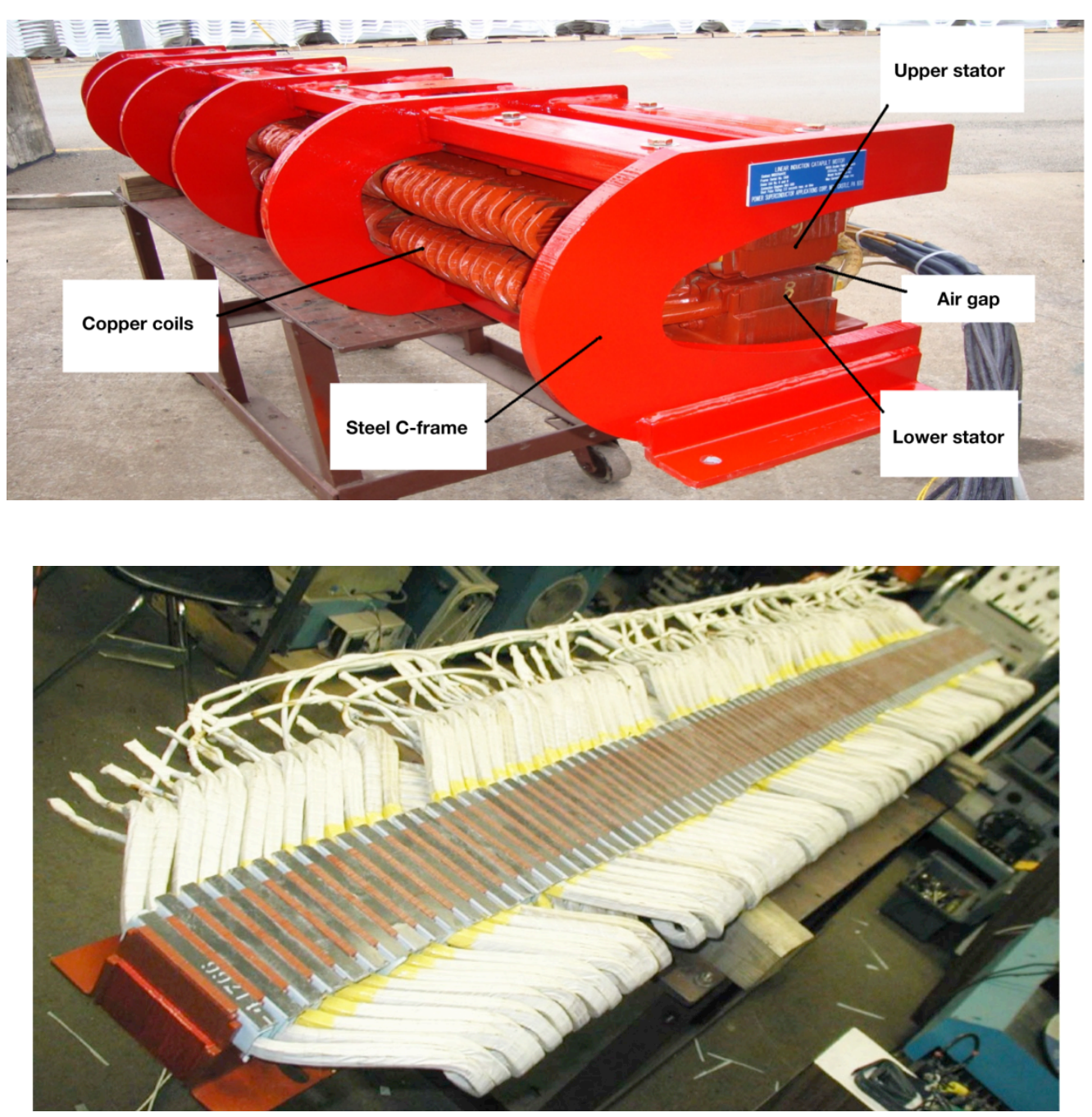


\section{LIM-CAT-85-2100 DSLIM}

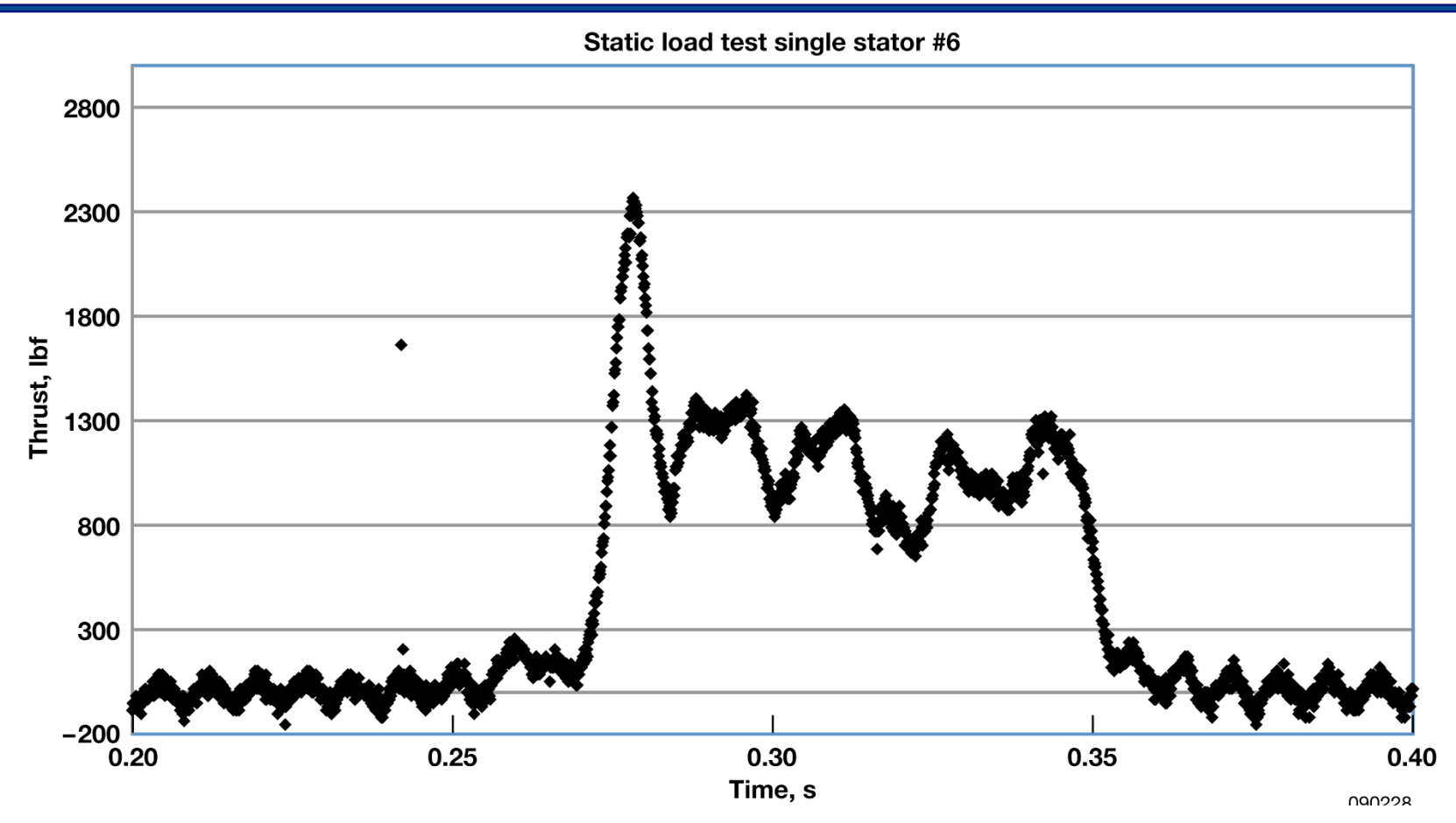

Static Test: Single-Sided -peak thrust of $2300 \mathrm{lbf}$ -average static thrust of $1167 \mathrm{lbf}$

Static Test: Double-Sided -peak thrust of $\mathbf{3 5 0 0} \mathrm{lbf}$ -average static thrust of 1900 lbf 


\section{General Atomics Urban Maglev Test Facility}
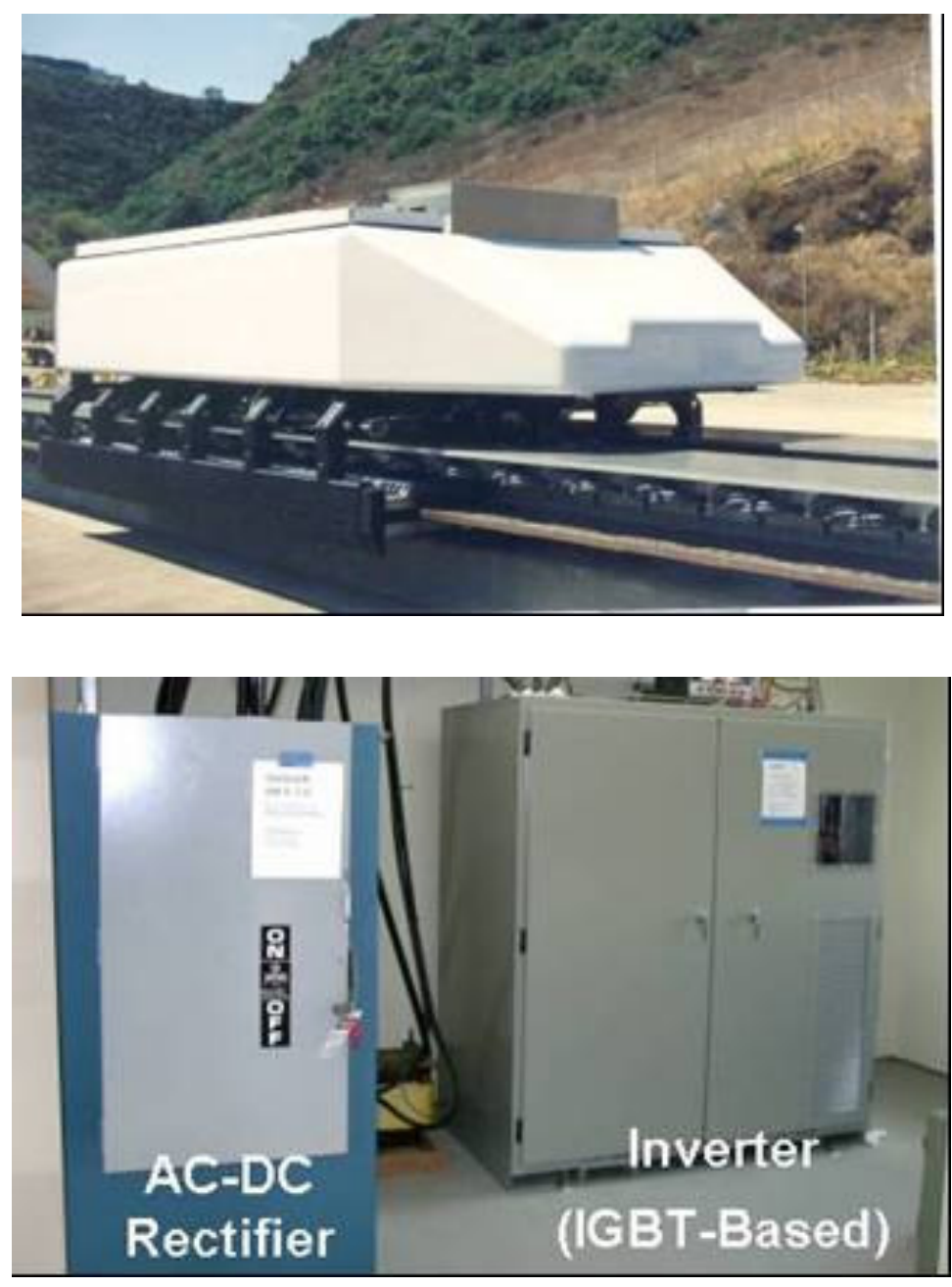

General Atomics IGBT-based urban maglev inverter:

- 480V three-level IGBT-based

- 2 MVA continuous to a load

- 20 MVA peak

- 11,000 A capacity to a load

- 0 to $1000 \mathrm{~Hz}$ 


\section{DSLIM Characterization and Testing}
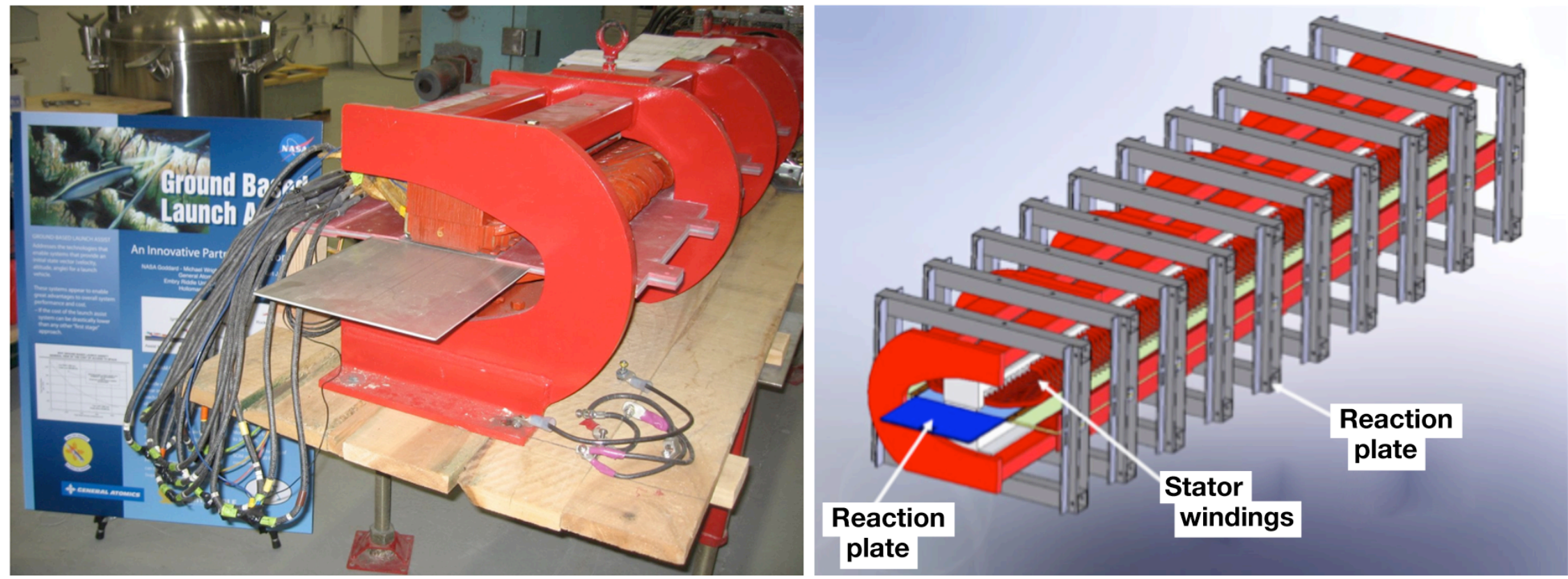

- Full Characterization and Simulation of DSLIM for optimal matching

- Design and construction of side force constraint system 


\section{Outline}

- Background/Analysis

- Virtual Isp and the Supersonic Barrier

- Gemini-Titan Reference and trajectory studies

- Hardware

- 60 Hz COTS Double Sided Linear Induction Motor

- 300 Hz Double Sided Linear Induction Motor

- Concepts

- Accelerator Design

- Ramjet Accelerator Concept Flight Envelope

- Summary 


\section{Towards Higher Speeds: 450Hz DSLIM Design}

\begin{tabular}{|l|l|}
\hline Parameter & Design value \\
\hline Power output & $7.01 \mathrm{MW}$ \\
\hline Output thrust & $5,000 \mathrm{lbf}$ \\
\hline Peak force & $\sim 13,000 \mathrm{lbf}$ \\
\hline Operating slip & $8 \%$ \\
\hline $\begin{array}{l}\text { Operating end } \\
\text { speed }\end{array}$ & $1,036 \mathrm{ft} / \mathrm{s}$ or $707 \mathrm{mph}$ \\
\hline $\begin{array}{l}\text { Number of stator } \\
\text { poles }\end{array}$ & $6 \mathrm{per}$ module \\
\hline Upper frequency & $450 \mathrm{~Hz}$ \\
\hline Overall length & $108 \mathrm{inches}$ \\
\hline Overall width & $\sim 20$ inches \\
\hline Overall weight & $3300 \mathrm{lb}$ \\
\hline Conductor type & Square cross-section Litz wire \\
\hline Reaction plate & $\begin{array}{l}\text { Aluminum } 0.25 " \text { thick, type } 1100 \\
\text { or } 6101\end{array}$ \\
\hline
\end{tabular}

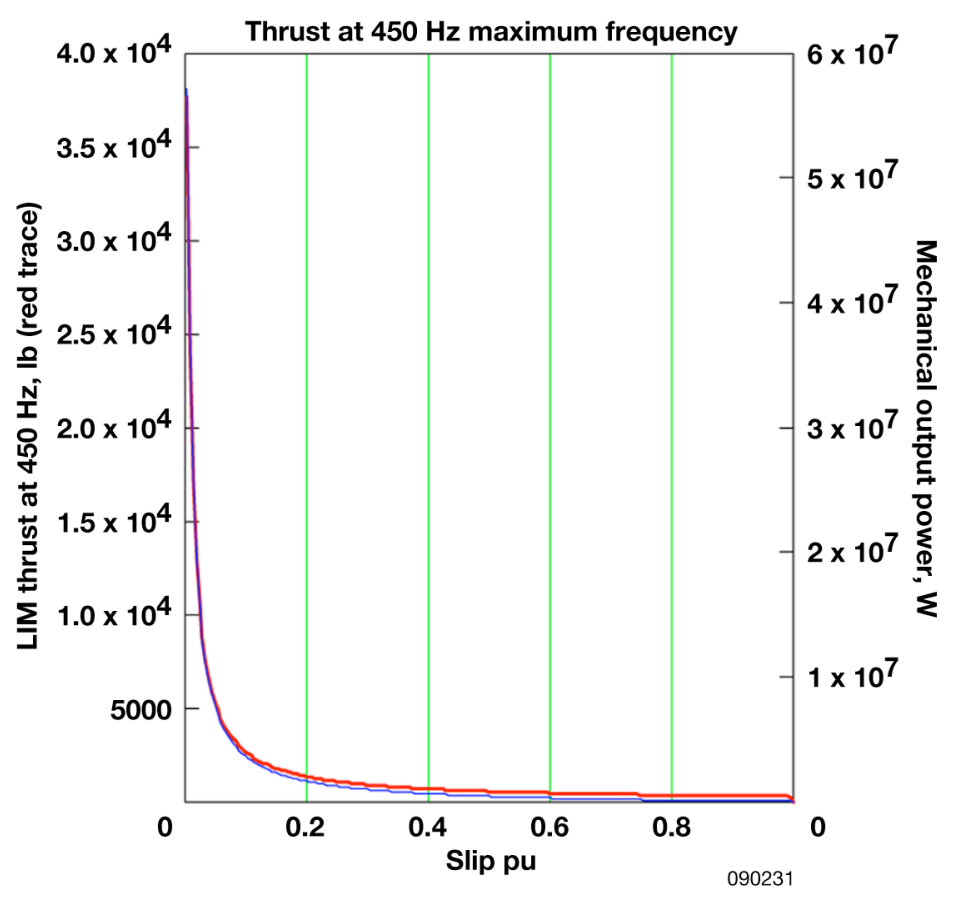

Higher Frequency Design

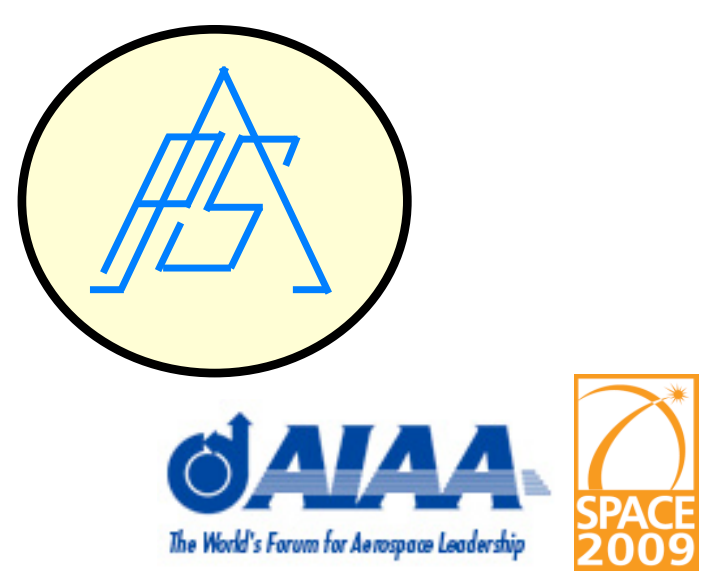




\section{Conceptual ramjet + supersonic launch-assist track}

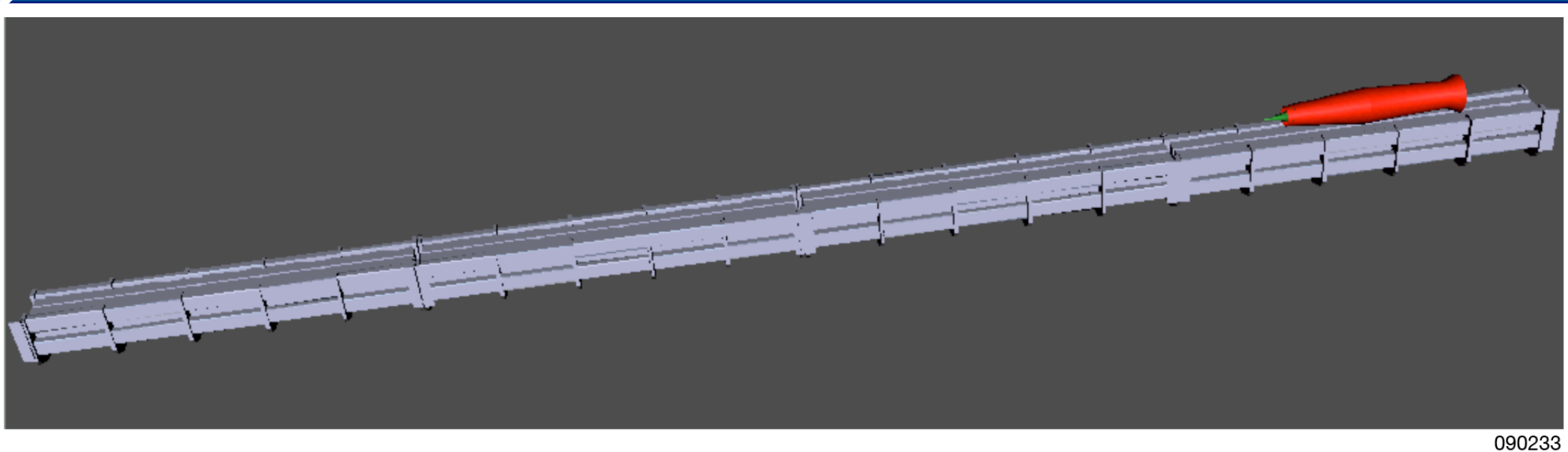

Initial assumptions:

Sea level to $10,000 \mathrm{ft}$ operation

Mach Number: 1.2 to 2

Burn duration: 2 to $5 \mathrm{~s}$

Gross wet weight:

between 50 and $100 \mathrm{lb}$

Acceleration detection limits:

1 to $10 \mathrm{~g}$ 's out of $500 \mathrm{~g}$ 's

Type of fuel: JP/kerosene
Initial calculations:

Acceleration: 3 to $5 \mathrm{~g}$ 's

Burn duration: 3 to $5 \mathrm{~s}$

$V_{\text {launch_assist }}=$ Mach 1.2

$V_{\text {final }}=$ Mach 1.6 to 1.9

Propellant mass fraction: $1 / 3$

Total ramjet weight: $20 \mathrm{lb}$

Net thrust: $60 \mathrm{lb}$

Fuel density: $50 \mathrm{lb} / \mathrm{ft}^{3}$

Fuel volume (JP-4): 30 to 50 in $^{3}$ 


\section{Ramjet Flight Envelope}

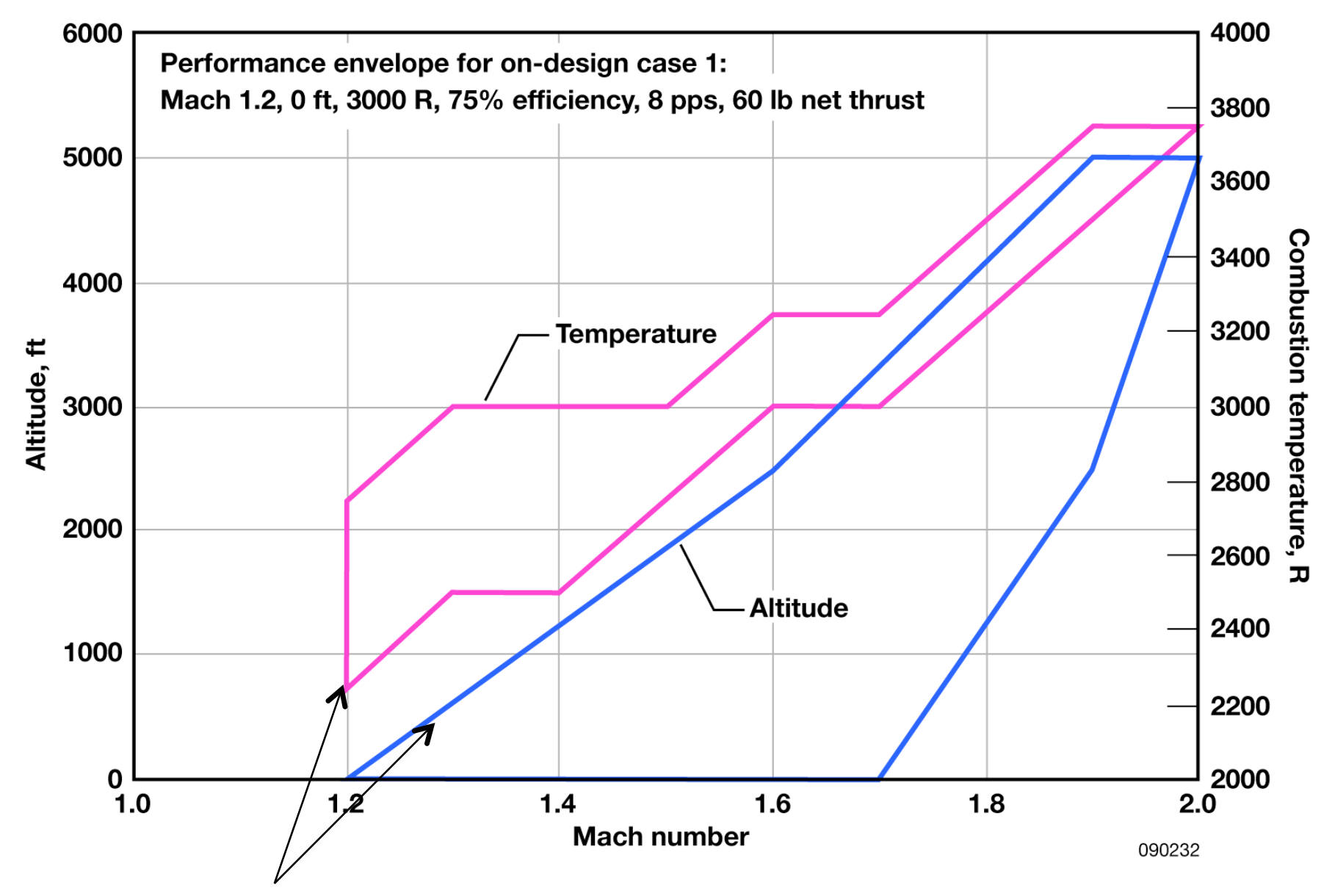

$60 \mathrm{Ibf}$ boundary 


\section{Summary}

- Analysis

- Supersonic Launch Assist $=29 \%$ increase in Isp_virtual.

- $\sim 48 \%$ reduction in GLOW/ 340 klb reference

- Experimentation

- COTS PWM inverter + 60Hz COTS DSLIM =10-lb@150 mph.

- Static load testing - $3500 \mathrm{lb}$ for one DSLIM

- Full characterization of $300 \mathrm{~Hz}$ DSLIM in voltage increments

- TRL bump

- Design

- Design $450 \mathrm{~Hz}$ linear motor

- $3500 \mathrm{lb}$ constraint system

- Concept design M1.2 ramjet 60 lbf thrust 


\section{Future Study Recommendations}

- System structure and weight analysis

- Dynamic pressure trajectory profile/Transonic structural

- RBCC/turbo-machinery/lifting surfaces.

- Ramjet design greater than $100,000 \mathrm{lbf}$

- Variable inlet geometries

- Variable fuels/mixing length

- Reliability/Lifetime Cost Studies

- Systems operations/maintenance costs/overall capital costs.

- Highly repetitive launch vehicles with fixed mission requirements

- Environmental system study

- chemical systems versus hybrid air-launch systems. 
Ignite RAM M1.5

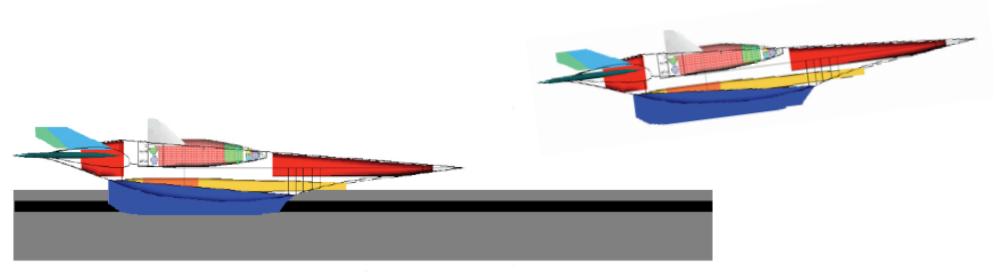

Separate M10
Rocket to Orbit

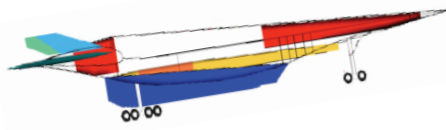

Runway Landing

\section{Questions?}

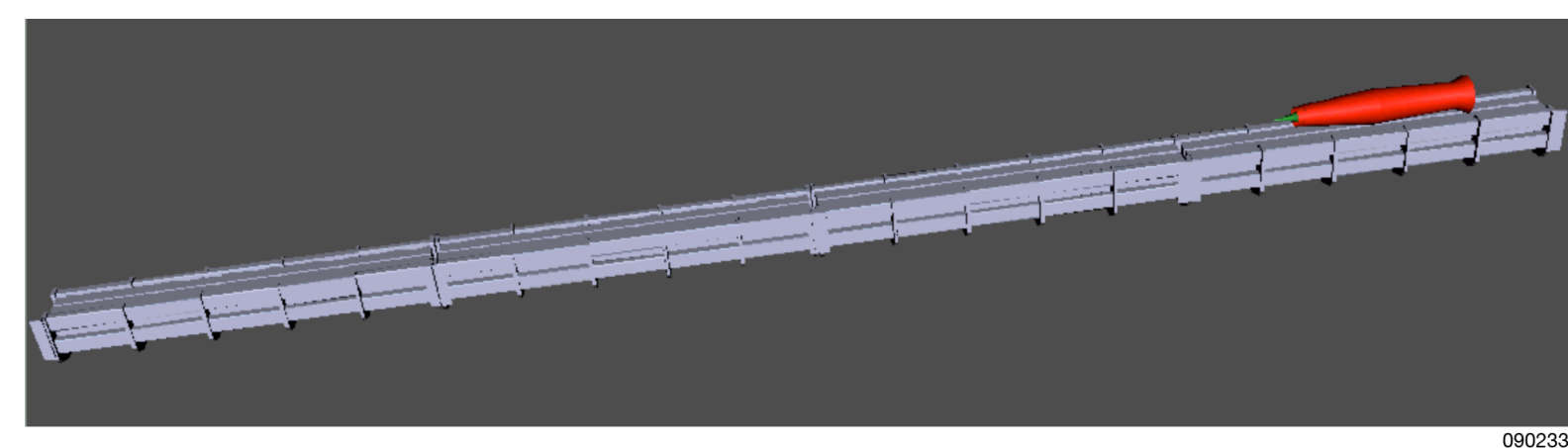

